G. Schlag H. Redl (Eds.)

\title{
Pathophysiology of Shock, Sepsis, and Organ Failure
}

With 540 Figures, some in Color, and 115 Tables

Springer-Verlag

Berlin Heidelberg New York London Paris

Tokyo Hong Kong Barcelona Budapest 
Günther Schlag, M.D.

Heinz Redl, Ph. D.

Ludwig-Boltzmann Institute

for Experimental and Clinical Traumatology

Donaueschingenstraße 13, A-1200 Vienna, Austria

\title{
ISBN 3-540-54223-X Springer-Verlag Berlin Heidelberg New York ISBN 0-387-54223-X Springer-Verlag New York Berlin Heidelberg
}

\begin{abstract}
This work is subject to copyright. All rights are reserved, whether the whole or part of the material is concerned, specifically the rights of translation, reprinting, reuse of illustrations, recitation, broadcasting, reproduction on microfilm or in any other way, and storage in data banks. Duplication of this publication or parts thereof is permitted only under the provisions of the German Copyright Law of September 9, 1965, in its current version, and permission for use must always be obtained from Springer-Verlag. Violations are liable for prosecution under the German Copyright Law.
\end{abstract}

(C) Springer-Verlag Berlin Heidelberg 1993

Printed in Germany

The use of general descriptive names, registered names, trademarks, etc. in this publication does not imply, even in the absence of a specific statement, that such names are exempt from the relevant protective laws and regulations and therefore free for general use.

Product liability: The publishers cannot guarantee the accuracy of any information about dosage and application contained in this book. In every individual case the user must check such information by consulting the relevant literature.

Typesetting: $\mathrm{K}+\mathrm{V}$ Fotosatz $\mathrm{GmbH}$, Beerfelden 23/3145-54 3210 - Printed on acid-free paper

UniveraltatoBibliothek Munchen 


\section{Table of Contents}

Introduction: "Organ in Shock", "Early Organ Failure",

"Late Organ Failure" (G. SCHLAG and H. REDL) .................

Trauma, Shock and Development of the Organ in Shock

and Early Organ Failure (SIRS) $\ldots \ldots \ldots \ldots \ldots \ldots \ldots \ldots \ldots \ldots \ldots \ldots \ldots \ldots$

Shock, Sepsis, and Multiple Organ Failure:

The Result of Whole-Body Inflammation (R. J.A. GoRIS) $\ldots \ldots \ldots \ldots \ldots 7$

The Role of Complement (M. Heideman and A. Bengtsson) ........ 25

Activation of Humoral Systems. The Role of Coagulation, Fibrinolysis, and the Plasma Kallikrein-Kinin System (A. O. AASEN and L. BUø) .... 36

Proteinases (M. Jochum, W. MACHLEIDT, H. NeUHOF, and H. FritZ) . . 46

Cellular Mechanisms of Leukocyte Adhesion

(ASRAR B. MALIK and YAN WANG) ......................... 61

Eicosanoids in Trauma and Traumatic Shock (H. NEUHOF) .......... 79

Radical Related Cell Injury

(H. REDl, H. GASSER, S. HAllströM, and G. SCHLAG) .......... 92

Humoral Mechanisms (D. B. HoYt, W. G. JUnGER, and A. N. OzKAN) . . 111

Monocyte and Lymphocyte Responses Following Trauma

(R. Stephan, A. Ayala, and I. H. Chaudry) ............... 131

Metabolic Response to Trauma

(J. Arnold, D. LeinhardT, and R. A. Little) ................ 145

Morphology of the Lung as a Consequence of Direct and Indirect Trauma (G. SchlaG, H. Redl, and J. Pretorius) $\ldots \ldots \ldots \ldots \ldots \ldots \ldots \ldots \ldots \ldots$

Permeability Changes (M. Seyr and N. J. Mutz) ............... 176

Cardiac Function During Hypovolemia

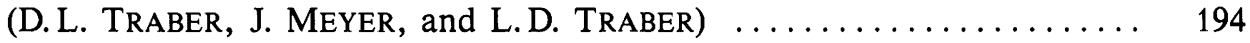

Cardiodepressant Factors

(S. HAllströM, B. Koidl, U. Mưller, K. Werdan, and G. SchlaG) .. 200

Response of the Macrocirculation (G. GUTIERREZ and S. D. BROWN) .... 215

Response of the Microcirculation: Tissue Oxygenation

(G. I. J. M. BEERTHUIZEN) . . . . . . . . . . . . . . . . . . . . . .

Cardiovascular Function in Acute Burns (C.S. Cox, Jr., D. L. TRABER, J. B. ZWISCHENBERGER, and D. N. HERNDON) $\ldots \ldots \ldots \ldots \ldots \ldots \ldots \ldots$ 
Morphology of the Liver in Shock

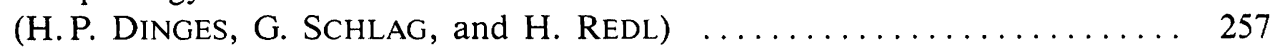

Bacterial Translocation (M. R. MAinous and E. A. DeITCH) ......... 265

Bacterial Translocation During Traumatic Shock in Baboons

(G. Schlag, H. Redl, J. Davies, C. J. J. van Vuuren, and P. Smuts) . . 279

Bacterial Translocation in Polytrauma Patients (B. F. RUSH, Jr.) . . . . . . 292

Bacterial Translocation in Burns

(S. T. Zeigler, D. L. Traber, and D. Herndon) $\ldots \ldots \ldots \ldots \ldots \ldots \ldots$

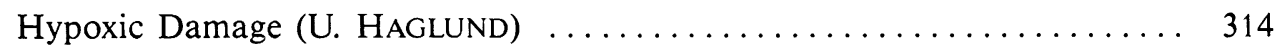

Reperfusion Injury in the Small Intestine (B. J. ZIMMERMAN, H. ARNDT, P. Kubes, H. Kurtel, and D. N. Granger) ............... 322

Kidney Blood Flow Changes in Shock (J. C. PASSMORE, J. T. Fleming,

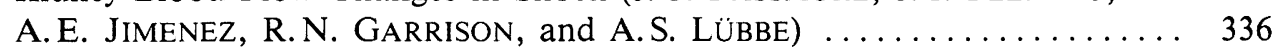

Central Nervous System Response to Trauma

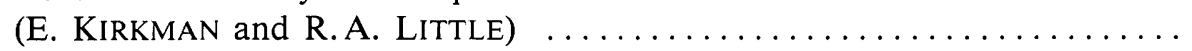

Rat and Mouse Models of Hypovolemic-Traumatic Shock

(I. H. Chaudry, P. Wang, G. Singh, J.G. Hauptman, and A. Ayala) ..

Hypovolemic-Traumatic Shock Models in Baboons

(G. SchlaG, H. Redl, Z. Khakpour, J. Davies, and J. Pretorius) ....

The Development of the Sepsis and Multi-Organ-Dysfunction-Syndrome

(MODS)

The Active Principle of Bacterial Lipopolysaccharides (Endotoxins)

for Cytokine Induction

(H. Loppnow, H.-D. Flad, E.T. Rietschel, and H. Brade) . ...... 405

LPS Plasma Levels in Patients (A. O. AASEN) ............... 417

Bacterial Exotoxins and Vascular Injury

(W. SeEger, N. Suttorp, F. GRimminger, and S. Bhakdi) . . . . . . 4 42'7

Complement in Sepsis (A. Bengtsson, H. RedL, and G. SCHLAG) . . . . . 447

Activation of Humoral Systems: Coagulation, Fibrinolysis,

and Plasma Kallikrein-Kinin Systems (A. O. AASEN and L. Buø) ........

The Cytokine Network in Trauma and Sepsis I: TNF and IL-8

(H. Redl, G. Schlag, S. Bahrami, J. Davies, A. WaAge, M. Ceska,

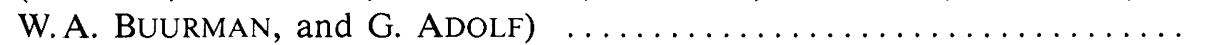

The Cytokine Network in Sepsis II: IL-1 and IL-6

(A. WaAge, H. Redl, G. SchlaG, and U. Schade) $\ldots \ldots \ldots \ldots \ldots$

Platelet-Activating Factor in Shock, Sepsis, and Organ Failure

(D. HOSFORD, M. KOLTAI, and P. BRAQUET)

Endotoxin Activation of Eicosanoid Production by Macrophages

(J.A. CoOK, J. Geisel, G. E. Tempel, W.C. Wise, and P. V. HalushKa) . 518

Proteolytic Enzyme Systems

(M. JOCHUM, W. MACHLEIDT, and H. FRITZ) 
Activation/Adherence Phenomena of Leukocytes and Endothelial Cells in Trauma and Sepsis (H. REDL, G. SCHLAG, R. KNEIDINGER,

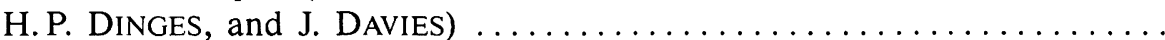

Procoagulant Response of the Endothelium and Monocytes

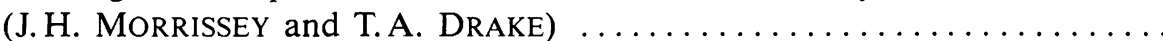

The Role of the L-Arginine Nitric Oxide Pathway in Sepsis

and Endotoxaemia with Special Reference to Vascular Impairment

(J. R. PARratt, J.-C. Stoclet, and I. Fleming) .................

Cytokine Modulation of Glucose Metabolism

(G. J. BAGBY, C. H. LANG, and J. J. SPITZER) $\ldots \ldots \ldots \ldots \ldots \ldots \ldots \ldots$

Mechanism of Insulin Resistance in Infection (C. H. LANG) $\ldots \ldots \ldots \ldots \ldots$

The Host Defense to Trauma and Sepsis:

Multiple Organ Failure as a Manifestation of Host Defense Failure Disease

(J. H. Siegel, S. Goodzari, P. Guadelupi, W.P. Coleman,

D. Malcolm, S. Blevins, D. Frankenfield, M. C. Badellino,

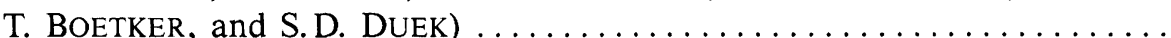

Experimentally Induced DIC - DIC as a Cause of MOF

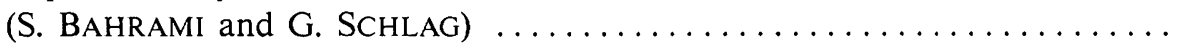

Three Clinical Presentations of E. coli Sepsis as Studied

in the Baboon Model (F.B. TAYLOR Jr. and S. D. KOSANKE)

Morphology of the Lung in Late Septic Shock

(E. A. PERKETT and B. MEYRICK)

Morphological Changes in Adult Respiratory Distress Syndrome:

Experimental and Clinical Data

(G. SchlaG, H. RedL, W. Öhlinger, and J. DaVies) .............

The Role of Respiratory Failure in Multiorgan Failure (R. C. BONE) . ....

Fibronectin and the Reticuloendothelial System: Relationship

to Lung Vascular Failure During Septic Shock (T. M. SABA) ...........

Abnormalities of the Lung Surfactant System in Acute Lung Injury

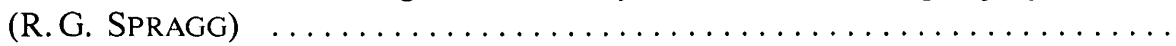

Experimental Models in Surfactant Research

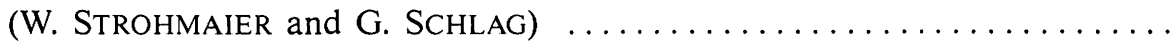

Myocardial Dysfunction in Experimental Shock (F. L. ABEL) ..........

"Negative Inotropic Cascades" in Cardiomyocytes Triggered by Substances

Relevant to Sepsis (K. Werdan, U. MÜller, and C. ReithmanN) .......

Myocardial Dysfunction in Experimental Septic Shock

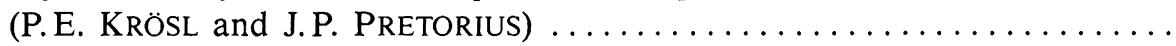

Pathomorphological Aspects of the Heart in Septic Patients

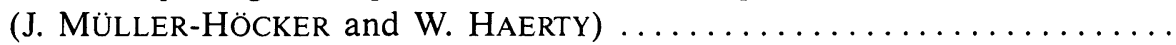

Clinical Manifestations of Cardiovascular Dysfunction in Sepsis

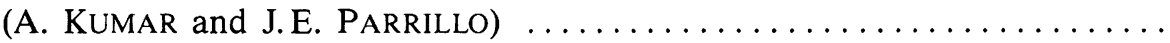

Coronary Hemodynamics and Myocardial Metabolism in Sepsis

and Septic Shock (J.-F. Dhainaut, J. Dall'Ava, and J.P. Mira) . . . . . .

Peripheral Macro- and Microcirculation (R. F. BOND) $\ldots \ldots \ldots \ldots \ldots \ldots$ 
Relationship Between Oxygen Demand and Oxygen Supply

in Severe Sepsis (J.-L. VINCENT, J. BAKKER, and P.-G. SilAnCE) . . . . . 908

Hepatic Responses to Bacterial Endotoxin (LPS) (A. P. BAUTISTA,

I. V. Deaciuc, H. JAeschKe, Z. Spolarics, and J. J. SPITZER) ....... 915

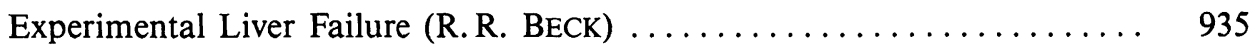

Hepatic Dysfunction in Shock and Organ Failure

(P.E. BANKey and F. B. CERra) $\ldots \ldots \ldots \ldots \ldots \ldots \ldots \ldots \ldots \ldots \ldots . \ldots \ldots$

Sepsis Related Renal Morphological Alterations
and the Functional Correlates (H. A. LINARES) $\ldots \ldots \ldots \ldots \ldots \ldots \ldots \ldots, 961$

The Kidney in Sepsis (A. S. TONNESEN) $\ldots \ldots \ldots \ldots \ldots \ldots \ldots \ldots \ldots \ldots$

Neurologic Abnormalities in Sepsis

(M. J. BRESLOW and R. J. TRAYSTMAN) .................. 996

The Multiple Organ or System Failure Syndrome (A. E. BAUE) ....... 1004

Models of Endotoxemia in Rodents

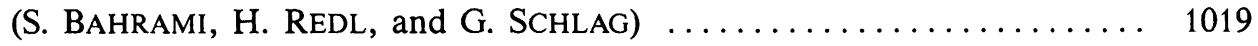

Models of Endotoxemia in Sheep

(D. L. Traber, L. D. Traber, H. RedL, and G. SchlaG) .......... 1031

Rodent Models of Endotoxemia and Sepsis

(I. H. Chaudry, A. Ayala, G. Singh, P. Wang, and J. G. Hauptman) • 1048

Sheep and Pigs as Animal Models of Bacteremia (D. J. DEHRING) ..... 1060

Live Escherichia coli Sepsis Models in Baboons

(G. SchlaG, H. Redl, J. Davies, C. J. J. van Vuuren, and P. Smuts) . . 1076

Animal Models of Endotoxemia and Sepsis (J. A. SPITZER) . . . . . . . 1108

Models of Sepsis: Subacute Peritonitis in Sheep and Rats

(C. M. Martin, A. NeAl, and W. J. SibBald) . . . . . . . . . . . . . 1119

Chronic Models of Endotoxemia and Sepsis: Lessons from Both

a Canine Peritonitis and a Human Endotoxemia Model

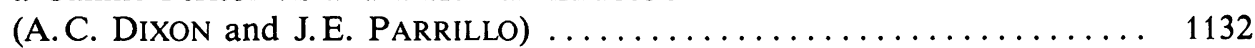

Subject Index $\ldots \ldots \ldots \ldots \ldots \ldots \ldots \ldots \ldots \ldots \ldots \ldots \ldots \ldots \ldots \ldots \ldots \ldots \ldots \ldots \ldots \ldots$ 


\title{
Proteolytic Enzyme Systems
}

\author{
M. Jochum ${ }^{1}$, W. MACHLEIDT ${ }^{2}$, and H. FRITZ ${ }^{1}$ \\ 'Department of Clinical Chemistry and Clinical Biochemistry in the Department of Surgery, Klinikum Innen- \\ stadt, University of Munich, Nußbaumstraße 20, 8000 Munich 2, FRG \\ ${ }^{2}$ Institute of Physiological Chemistry, Physical Biochemistry and Cell Biology of the University of Munich, \\ Goethestraße 33, 8000 Munich 2, FRG
}

\section{CONTENTS}

Introduction $\ldots \ldots \ldots \ldots \ldots \ldots \ldots \ldots \ldots \ldots \ldots, 531$

Methods ...................... 532

Polymorphonuclear Granulocyte Elastase

and Macrophage-Derived Cathepsin B Release

in the Septic Course $\ldots \ldots \ldots \ldots \ldots \ldots \ldots$

Plasma Levels of the Phagocyte Proteinases

in Relation to the Severity of the Disease

and the Consumption of Clotting Proteinases

and Antithrombin III ...............

Plasma Levels of Polymorphonuclear

Granulocyte Elastase-Induced Split Products

of Vital Proteins as Indicators

of Unspecific Proteolysis in the Circulation . 536

Polymorphonuclear Granulocyte Elastase

and Cathepsin B in Peritonitis Exudates

in Relation to the Local Degradation

of Vital Proteins

532

537
Conclusions

538

Proteinase Inhibition as a Convenient

Therapeutic Approach in Septic Multiple Organ

Failure $\ldots \ldots \ldots \ldots \ldots \ldots \ldots \ldots \ldots \ldots \ldots \ldots \ldots \ldots$

Inhibitors of Polymorphonuclear Granulocyte

Elastase or Thrombin

in Experimental Septic/Endotoxin Shock ....

Systemic Supplementation

of Antithrombin III in Clinical Sepsis ......

Local Administration of Serum in Peritonitis

Conclusions ....................... 544

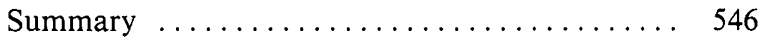

References ................... 546

\section{Introduction}

Sepsis has traditionally been defined as a systemic inflammatory reaction of the organism to gramnegative bacterial leading to septic shock and eventually to (septic) multi-organ failure. Interestingly, it has become evident that the final common pathways of multi-organ failure initiated by trauma or by infection are very similar involving basically the same humoral and cell-dependent effectors and mediators. Amongst these, proteolytic enzyme systems have been suggested to play an equally important role in the course of sepsis-like syndrome and trauma-induced inflammatory response. As outlined in the chapter by Jochum et al. (pp 46-60), the lysosomal serine proteinase elastase and the cysteine proteinases cathepsins B and $\mathrm{L}$ of the primary inflammatory cells, polymorphonuclear (PMN) granulocytes and monocytes/ macrophages, respectively, are thought to be particularly potent effectors of proteolytic tissue damage if they are discharged extracellularly in high amounts during activation and disintegration of the phagocytes due to multiple trauma or sepsis. The initial mechanisms of stimulation in these inflammatory processes, however, are significantly different. Bacterial endotoxin and other bacterial products, e.g., exotoxins, $\mathrm{N}$-formylated peptides, and bacterial proteinases but also antigen-antibody complexes have been identified as potent stimulators of the inflammatory response to infection.

Although in more recent studies, gram-negative bacteria have not been recognized as the etiologic agent in more than half of the patients presenting symptoms of sepsis-like syndrome (Glauser et al. 1991), the effects of bacterial endotoxin, a lipopolysaccharide (LPS) from the cell wall of gram-negative bacteria, have been characterized in detail in numerous studies. Endotoxin administration to human volunteers activated most of the relevant humoral and cellular cascade systems and produced cardiovascular changes that were qualitatively similar to those seen in septic shock (Parrillo et al. 1990). Though endotoxin is able to produce sep- 
tic shock, it seems to be only one of several bacterial products that can initiate or enhance the septic response. However, as a well-defined substance, bacterial LPS has become a valuable tool in various animal models of septic shock, one of which will be discussed in this chapter.

Due to species differences in the inflammatory response, results obtained in animal experiments are only partially valid for the sepsis-like syndrome of patients. Considerable differences between animal models and human septic shock have been revealed with respect to proteolytic enzymes and their endogenous inhibitors. Thus, the most relevant data on the role of proteinases, especially concerning PMN elastase and cathepsin $\mathrm{B}$, in human sepsis have been obtained from clinical studies, as reviewed below. In addition, preliminary results will be discussed on the effect of proteinase inhibitor substitution in septic patients. The local response observed in patients with diffuse peritonitis provided us with further insight into the proteolytic pathomechanisms of inflammation and their possible modulation by proteinase inhibition during sepsis-like multiple organ failure.

\section{Methods}

Serially drawn citrated plasma ( $2-4$ specimens per day) and peritonitis exudate samples were used to quantify proteinases, inhibitors, and other proteins and their split products. The biochemical methods applied are outlined in detail in the chapter by Jochum et al. (pp 46-60).

Clinical methods, criteria for grading the severity of the infectious disease and organ failure, treatment of patients, and the protocol of the experimental therapeutic studies are extensively described in the original publications cited in the following sections.

\section{Polymorphonuclear Granulocyte Elastase and Macrophage-Derived Cathepsin B Release in the Septic Course}

\section{Plasma Levels of the Phagocyte Proteinases in Relation to the Severity of the Disease and the Consumption of Clotting Proteinases and Antithrombin III}

In several prospective clinical studies on more than 200 patients suffering from bacterial infections after major surgery, we could demonstrate an increasing release to PMN elastase into the circulation in accordance with the worsening of the inflammatory reaction (Fig. 1 a) (Duswald et al. 1985; Inthorn and Jochum 1988; Jochum 1988; Jochum et al. 1990). Patients without postoperative infections showed only moderate transiently elevated plasma levels of complexed elastase (up to three times that of normal) after operation, whereas onset and course of sepsis were characterized by markedly increased concentrations up to 30 -fold in individual patients. As a mean, in patients with persisting septicemia the elastase plasma levels remained significantly elevated until death, while a recovery phase was accompanied by an obvious return to normal values. A detailed evaluation of our data (Jochum 1988; Inthorn and Jochum 1988) showed that in eventually dying patients a significant increase of complexed elastase occurred 2-3 days before clinical manifestation of severe sepsis, followed by a transient decrease and an additionally significant rise, when sepsis was clinically diagnosed (Fig. 2). In surviving patients, however, the tremendous increase of PMN elastase in plasma did coincide with the clinical manifestation of the severe infection, whereas the recovery phase was clearly indicated earlier by declining elastase levels compared to the clinical assessment (Fig. 2). Thus, measuring PMN elastase in closely matched consecutive plasma samples (taken every $6 \mathrm{~h}$ ) of severely ill patients did not only allow an early diagnosis of the clinical state, but also suggests an involvement of the granulocytic proteinase in the development of severe infection and sepsis.

In addition, we could demonstrate for the first time, in some pilot studies, that especially during a lethal septic course the monocyte/macrophage-derived cathepsin B was released in a manner similar to the PMN elastase, suggesting that discharge of lysosomal cysteine proteinases may intensify the extracellular proteolytic capacity (Fig. 3).

When complexed elastase and cathepsin B increased in plasma, a prominent reduction of the humoral blood cascade proenzymes prekallikrein (Fig. 1 b) and prothrombin (Fig. 1 c) and of antithrombin III (AT III) inhibitory activity (Fig. 3b) was measurable. This indicates that the proteolytic mechanisms in this pathological situation are quite similar to those seen in the course of developing posttraumatic organ failure (see the chapter by Jochum et al., pp 46-60). Results confirming our findings with respect to the release of PMN elastase and the consumption of hemostatic proteins in more than 150 patients developing infection and 


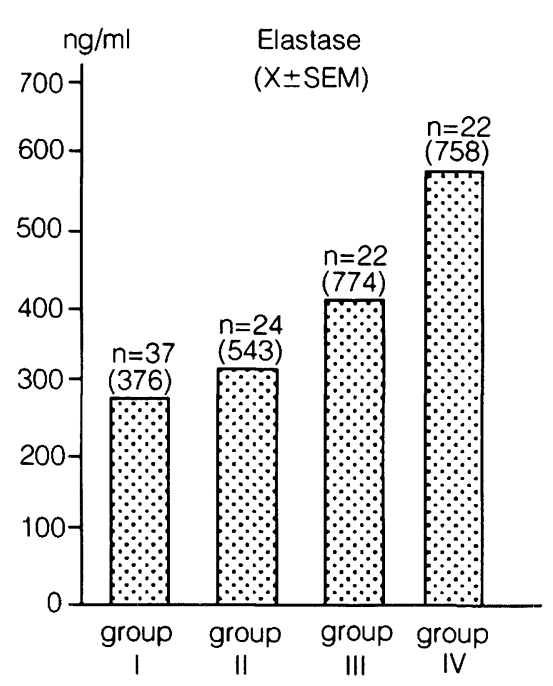

a

Fig. 1. Plasma levels (mean \pm SEM) of a PMN elastase (in complex with $\alpha_{1}$-proteinase inhibitor), b kallikrein, and $\mathbf{c}$ prothrombin, according to the severity of postoperative inflammation: group $I$, without postoperative complications; group II, wound infection and limited peritonitis; group III, widespread soft-tissue inflammation and peritonitis $>1$ quadrant; group $I V$, clinically ensured sepsis; $U=$ unit $/ \mathrm{ml} ; 1 U \hat{=}$ normal plasma value; number in parentheses, number of single determinations in each group

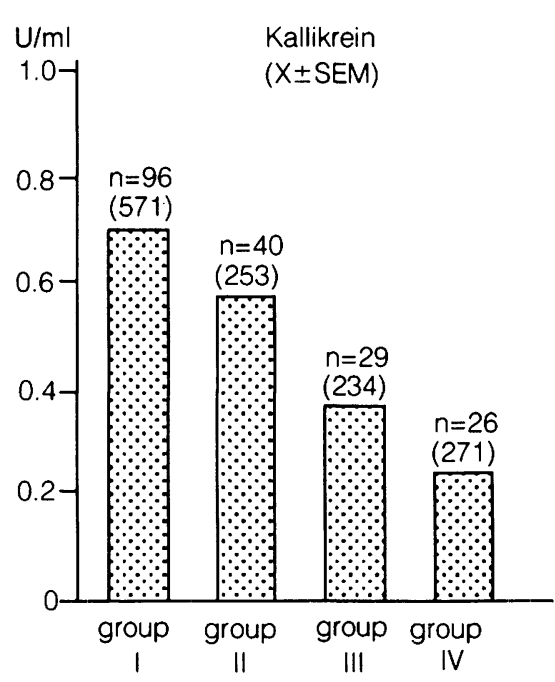

b

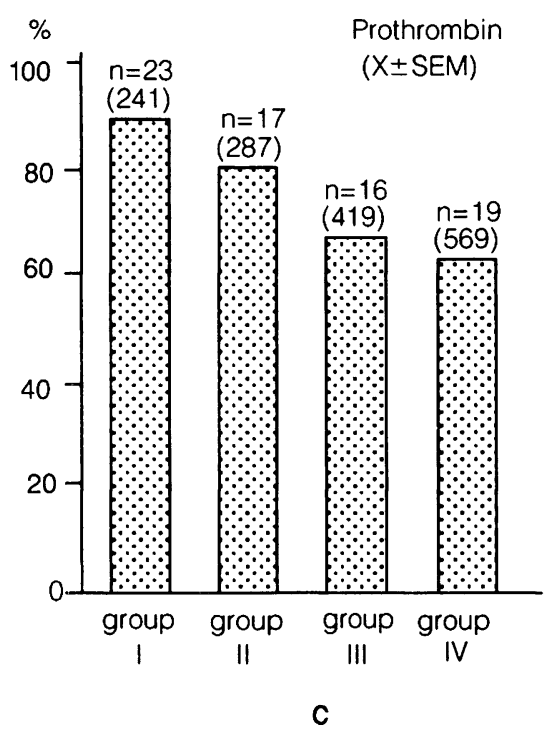

nonseptic patients, whereas septic survivors showed high levels equal to those of nonseptic postoperative patients. Moreover, septic pulmonary insufficiency could be predicted 1 day before the need for mechanical ventilation by elastase levels above 4-fold that of normal with a specificity of $80 \%$ and a sensitivity of $81 \%$. With an even higher specificity $(83 \%)$ and sensitivity $(88 \%)$ this threshold level predicted multiple organ failure (MOF) 1 day before a MOF score of $>5$ was evaluated. These results can be taken as a further hint of the pathogenic potency of PMN elastase in the development of sepsis and MOF regardless of the inciting cause.

The predictive validity of PMN elastase plasma levels for a forthcoming postoperative infection levels was seen between septic nonsurvivors and 


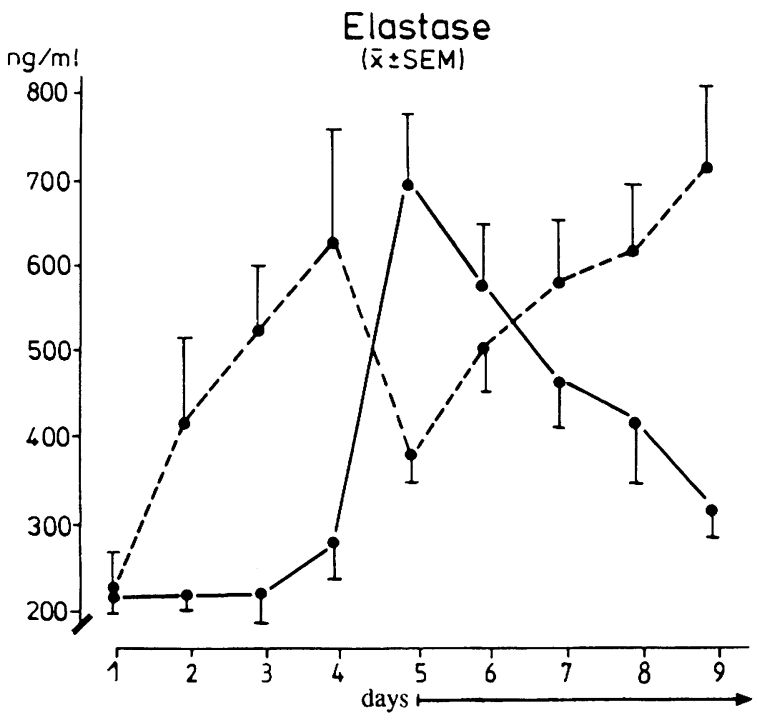

Fig. 2. Plasma levels of PMN elastase (in complex with $\alpha_{1}$-proteinase inhibitor) in patients developing severe infection/sepsis. Days 1 to 4: clinical course with minor or without complications; days 5 to 9: clinically diagnosed life-threatening infection/sepsis; dotted line, nonsurvivors $(n=11)$; solid line, survivors $(n=11)$
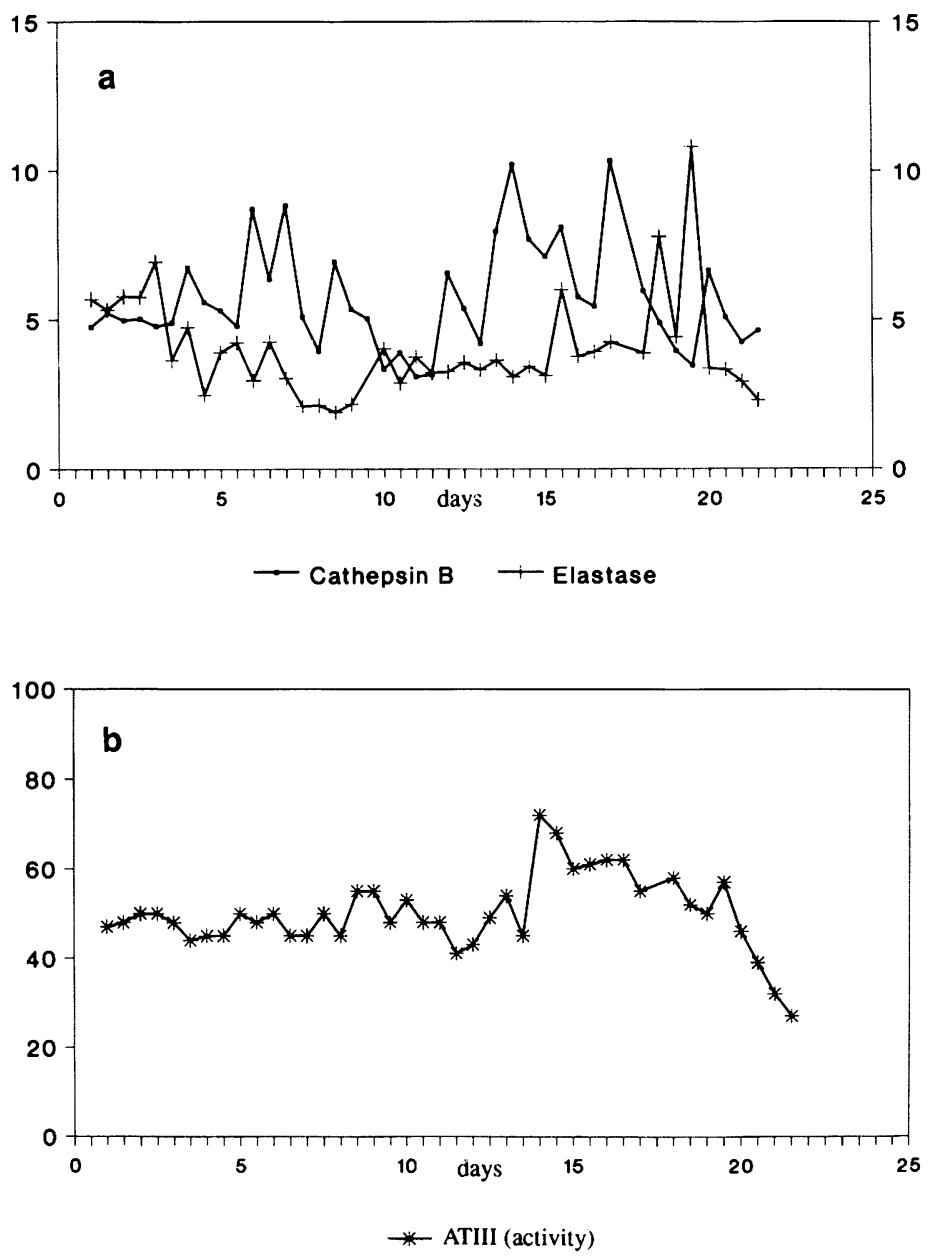

Fig. 3. a Cathepsin B activity and PMN elastase (in complex with $\alpha_{1}$-proteinase inhibitor) in plasma of a patient with lethal sepsis, expressed in multiples of normal. b Antithrombin III inhibitory activity in plasma of the same patient, expressed as $\%$ of normal 
risk was also confirmed by Fink et al. (1989). In 12 of 25 patients with colon-related surgical operations the complexed elastase in plasma was still significantly elevated above normal on the 5th postoperative day, thereby indicating a forthcoming infection at least 3 days before the clinical verification of the complication on day 8-10. In uncomplicated cases a steady decrease after the operation-induced elevation was noticed. In another study of this research group (Fink et al. 1988), involving 56 intensive care patients undergoing abdominal surgery, the operation procedure induced a 3-fold increase of elastase plasma levels in 31 patients with an uncomplicated postoperative course, whereas in patients with an early postoperative sepsis a more than 5-fold elevation above normal was measured. Ten patients who survived the septic episode where characterized by a steady decrease of complexed elastase and could not be differentiated from those without sepsis from the 48th postoperative hour onwards. Septic nonsurvivors $(n=15)$, however, showed constantly high or even additionally increasing postoperative elastase levels. Thus, the authors concluded that a long lasting elevation of PMN elastase is highly indicative of a serious deterioration of the septic situation.

Just recently, Tanaka et al. (1991) compared daily measured elastase plasma levels of 16 patients with septic shock complicated by MOF with those of 30 patients with hemorrhagic shock secondary to severe injury over a period of 1 week. Whereas in the septic patients the shock period lasted for more than 7 days, patients suffering from severe injury recovered from hemorrhagic shock within $24 \mathrm{~h}$. At diagnosis of septic shock complexed elastase was elevated up to a mean plasma level of 8 -fold that of normal and remained high during the ensuing week. In hemorrhagic shock the levels were also raised up to about 6 -fold but quickly returned to normal at recovery. In this study the increase in complexed elastase in plasma was significantly correlated with decreases of plasmatic fibronectin and factor XIII, two proteins known to be easily susceptible to proteolytic cleavage by PMN elastase (reviewed by Jochum 1988). Significant correlation was also found between elastase activity in bronchoalveolar lavage fluid (BALF) samples and the respiratory index of the septic shock patients, thus suggesting that at least local tissue damage in sepsis and MOF may be in part due to the destructive potency of PMN elastase.

Likewise, a highly significant positive correlation between the plasma levels of complexed elas- tase and the respiratory index was reported by Shimanuki et al. (1989) in 49 patients who underwent operations of various degrees of surgical stress. As the operative intervention became more severe, the plasma levels of granulocytic elastase rose. Moreover, marked and prolonged elevation of these plasma levels paralleled postoperative pulmonary complications. Patients with panperitonitis already showed mean complex plasma levels of more than 7 -fold over normal before operation, whereas in noninfectious underlying diseases only slightly elevated preoperative elastase levels were measured. Coinciding with our findings (Duswald et al. 1985) the elastase complex levels in patients with panperitonitis did not increase after surgery but slightly decreased over time, probably due to the removal of the abdominal inflammatory focus enabling a continuous amelioration of the infection.

Schöffel et al. (1989a) studied a collective of 21 patients undergoing major abdominal surgery in whom sepsis was diagnosed during their postoperative stay on the ICU. A persistent elevation of complexed elastase above 4-fold that of normal plasma values beyond the third postoperative day or an additional increase (5- to 10-fold) closely correlated with postoperative intraabdominal infectious complications which required reintervention. In those patients $(n=7)$ sepsis was clinically diagnosed between the third and sixth postoperative day. $\mathrm{Pa}$ tients with transient postoperative septic episodes showed a gradual normalization of elevated elastase plasma levels within the first 3-4 days after surgery. In another study monitoring the early inflammatory response in 27 peritonitis patients, the authors emphasized the significant predictive value of elevated elastase plasma levels at the time of emergency laparotomy for the later outcome (survival/death) of the patients (Schöffel et al. 1989b).

In addition to measurements of the complexed elastase in plasma of adults, serial quantifications of this granulocytic proteinase in 306 neonates, carried out by Speer and Tegtmeyer (1989), have proven that this inflammatory mediator is both a highly sensitive and rapidly responsive indicator of neonatal septicemia and a helpful tool in monitoring the course of the disease. When patients with neonatal septicemia were differentiated from those with other neonatal disorders, elevated complexed elastase levels showed a sensitivity of $95 \%$ and specificity of $81 \%$ for the septic entity. Similar results were published by Tsaka and Herkner (1990) on 135 newborn infants. 


\section{Plasma Levels of Polymorphonuclear Granulocyte Elastase-Induced Split Products of Vital Proteins as Indicators of Unspecific Proteolysis in the Circulation}

Just recently we were able to verify the destructive proteolytic potency of PMN elastase in a still ongoing prospective study (clinically directed by Dr. Inthorn, Department of Surgery Großhadern, University of Munich) of septic patients. To be enrolled in this investigation, patients had to fulfill all four previously defined septic criteria (septic focus and/or positive blood culture; body temperature $>38.5^{\circ} \mathrm{C}$; leukocytes $>15000 / \mu \mathrm{l}$ or $<5000 / \mu \mathrm{l}$; platelets $<100000 / \mu$ l or drop in platelets $>20 \%$ within $24 \mathrm{~h}$ ensuring a severe inflammatory situation. In patients with lethal outcome, the generation of the elastase-induced fibrinogen split product "fibrinoelastase peptide (FEP)" (Gippner-Steppert 1991; see also the chapter by Jochum et al., pp 46-60) in the circulation was well correlated to high plasma levels of PMN elastase (Fig. 4). Moreover, the unspecific proteolytic degradation of AT III, which is also susceptible to PMN elastase cleavage (Jochum et al. 1981; Jordan et al. 1989), could be pointed out by an indirect method comparing the amount of AT III antigen with its inhibitory activity (Fig. 5). In patients suffering from eventually lethal sepsis AT III was not only considerably consumed (to about $50 \%$ of normal) throughout the whole sepsis period, but the clearly lower inhibitory activity (between $20 \%$ and $40 \%$ ) also indicated that part of the antigen level may be due either to inactive complexes of the inhibitor with clotting enzymes or to proteolytically degraded molecules. Since the latter have an only slightly lower molecular weight and nearly the same half-life as the intact molecules (Jordan et al. 1989), they cannot be distinguished from the native AT III if quantified by radial immunodiffusion. In our patients, however, we could definitely rule out the possibility that AT III-proteinase complexes contribute to a significant degree of the higher antigen levels in comparison to the inhibitory activity. Due to their very short half-life of only a few minutes, concentrations of AT IIIthrombin complexes made up at most only $0.01 \%$ of the overall AT III amount. Thus, elastase-inactivated AT III molecules should be present with high probability in the pathological situation of severe sepsis. This assumption is further supported by results of Jordan et al. (1989) which demonstrated that even catalytic amounts of heparin react with elastase in a way considerably accelerating the rate of AT III inactivation by this enzyme. Since heparin exists not only as a minor component on vascular endothelial cells but is also used as a therapeutic drug in our patients, the positive regulation of hemostasis by heparin may be clearly counteracted by the adverse effect on AT III in case of a high release of elastase from PMN granulocytes adhering to the endothelial layer of the blood vessel walls. Moreover, as shown just recently by Frommherz et al. (1991), inhibition of elastase by $\alpha_{1}$-proteinase inhibitor $\left(\alpha_{1} \mathrm{PI}\right)$ is significantly retarded in the presence of heparin, which would further allow proteolytic degradation of susceptible plasma proteins.

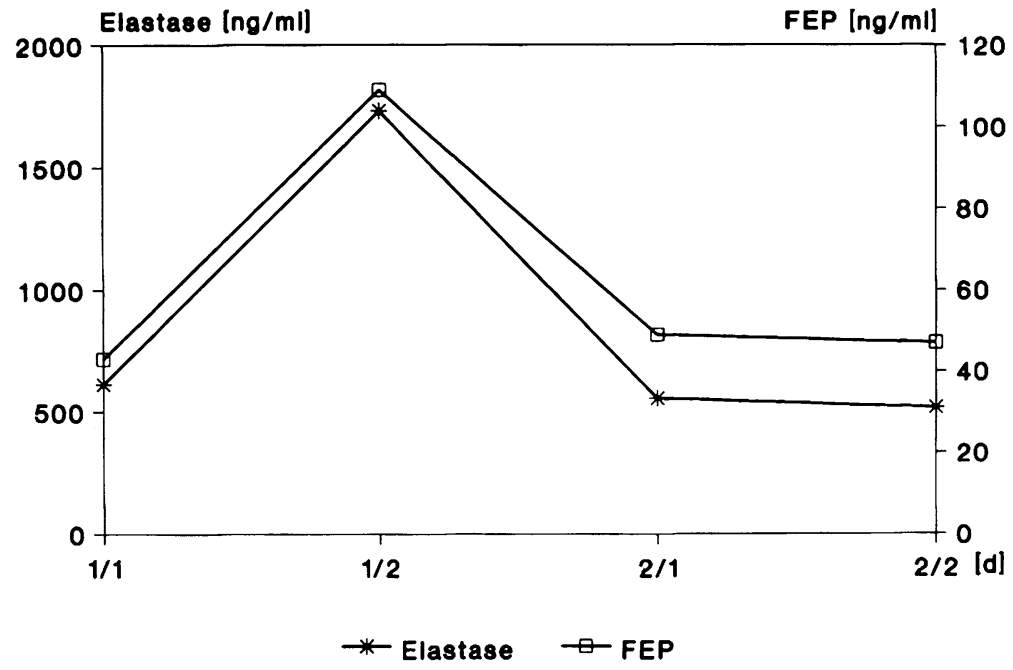

Fig. 4. Plasma levels of PMN elastase (in complex with $\alpha_{1}$ proteinase inhibitor) and fibrinoelastase-peptide $(F E P)$ in a patient with lethal outcome 2 days after diagnosis of sepsis due to bifurcation malacia of the trachea 
Fig. 5. Comparison of antithrombin III ( $A T$ III) immune reactive levels (immun.) and inhibitory activity (act.) in plasma samples of a patient with lethal sepsis

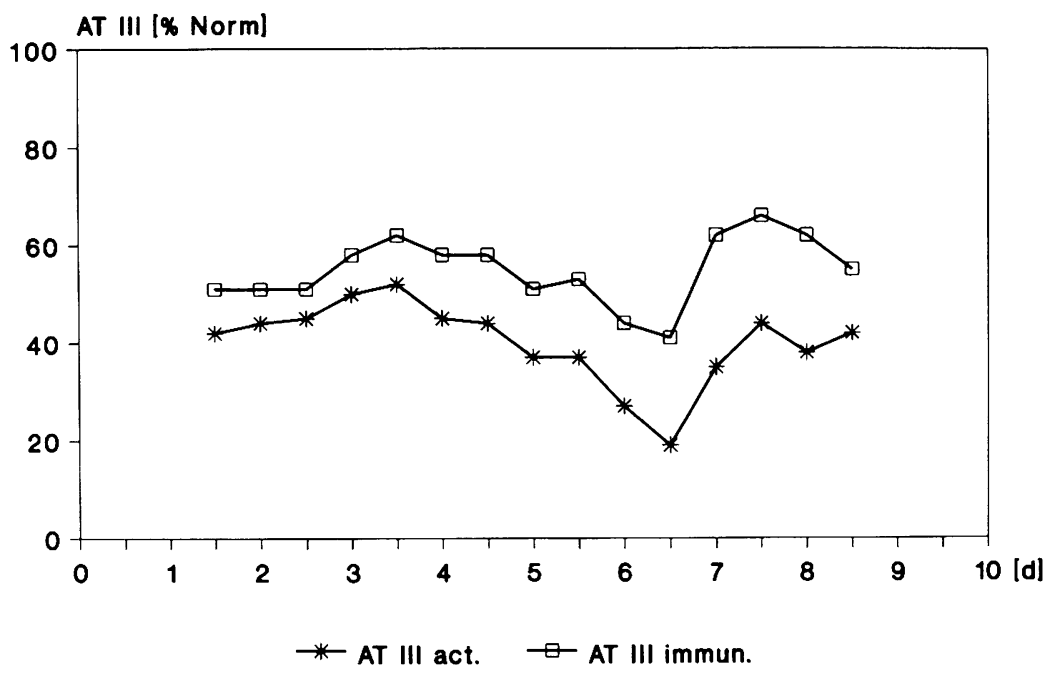

\section{Polymorphonuclear Granulocyte Elastase and Cathepsin B in Peritonitis Exudates in Relation to the Local Degradation of Vital Proteins}

Diffuse peritonitis is often the source of a systemic spreading of local infectious complications eventually leading to sepsis and MOF. In a previous work we were able to demonstrate that the impairment of opsonization in the peritoneal cavity allows the survival of huge numbers of bacteria, despite the presence of intact phagocytes (Billing et al. 1988 a, b, 1989). Since the proteolytic breakdown of the main opsonins IgG and complement factor $\mathrm{C} 3$ in peritonitis exudates correlated well with the extracellularly released lysosomal proteinases, elastase and cathepsin B, in the local body fluids, we assumed that these enzymes are the principal cause of the deficiency in opsonic capacity (Fig. 6). To test this hypothesis, isolated IgG was incubated in vitro either with $\mathrm{PMN}$ elastase and cathepsins $\mathrm{B} / \mathrm{L}$ or (in its isothiocyanate-labeled form $=$ FITC-IgG) with a cell-free, purulent peritonitis exudate (kindly supplied by Dr. Billing, Department of Surgery Großhadern, University of Munich). The proteolytic degradation was followed by gel chromatography of the split products (Fig. 7) which exhibited a similar type of IgG cleavage pattern under all conditions (Machleidt et al. 1993; Billing et al. 1991). Using the specific inhibitor E-64 we were able to demonstrate that part of the in vitro IgG cleavage by peritonitis exudates was due to cysteine proteinases such as cathepsin B or L. Yet, the major portion of the proteolytic activity was abolished by
Fig. 6. Opsonic capacity (determined by chemiluminescence assay), cathepsin B activity, and PMN elastase (in complex with $\alpha_{1}$-proteinase inhibitor) in peritonitis exudates $(n=28)$

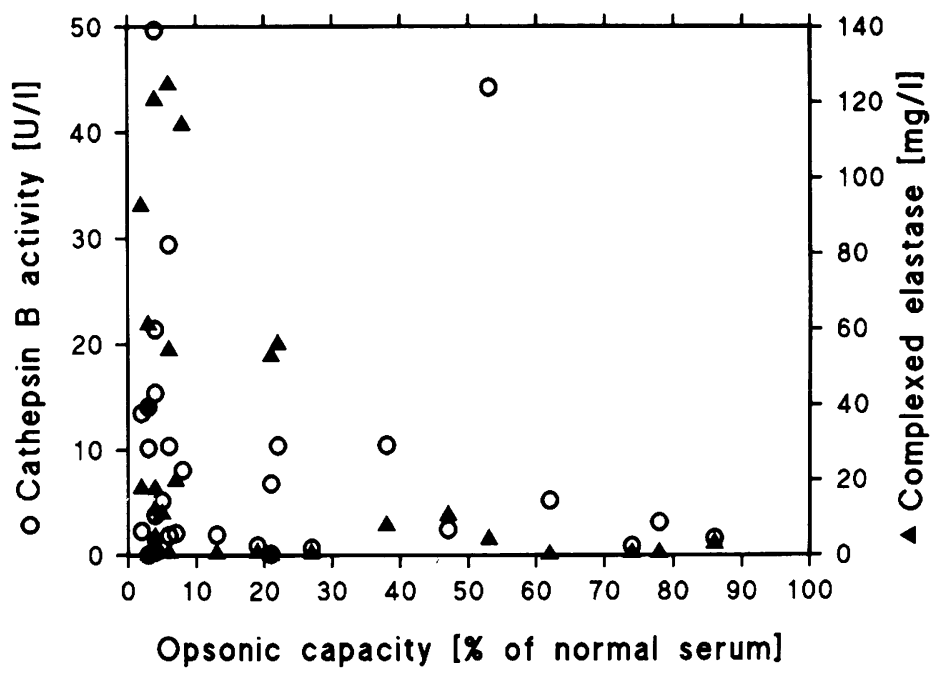



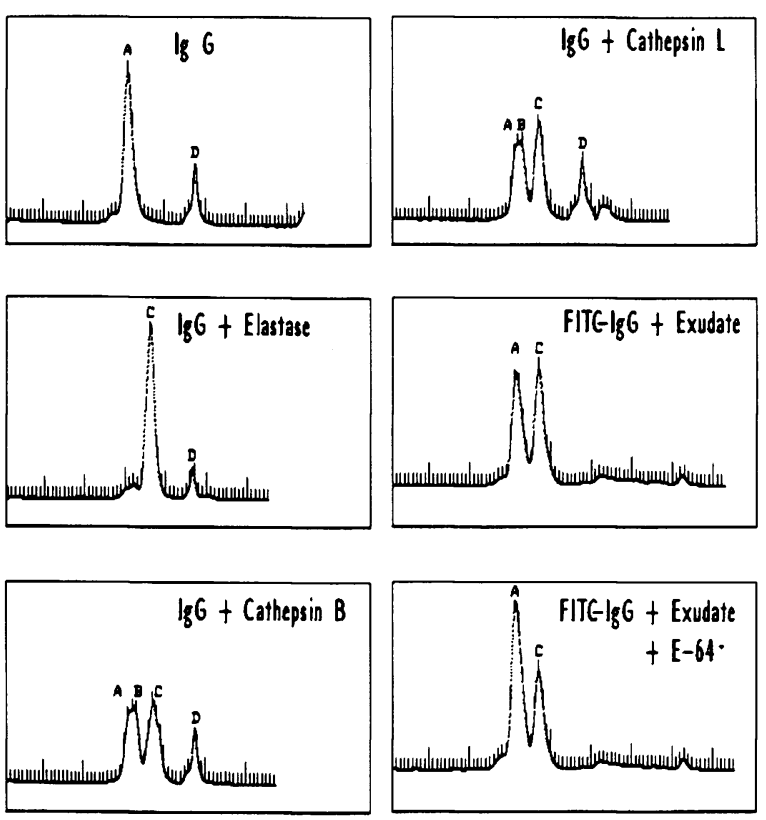

Fig. 7. Limited proteolysis of isolated human immunoglobulin $\mathrm{G}(\mathrm{IgG})$ and fluorescein isothiocyanate labelled IgG (FITC-IgG) by isolated lysosomal proteinases (PMN elastase, cathepsins $B, L$ ) and peritonitis exudate, respectively. IgG and $\mathrm{IgG}$ fragments were separated by fast gel chromatography on a Superose 12 FPLC column. $A$, intact $\mathrm{IgG} ; B,(\mathrm{Fab})_{2}$ fragments; $C, \mathrm{Fc}$ and/or Fab fragments; $D$, low molecular mass buffer artifact present in all samples. $E-64$, a specific inhibitor of the cysteine proteinases cathepsin B and L which suppresses the cathepsin-related proteolytic activity in the exudate

addition of $\alpha_{1}$ PI substantiating proteolytic elastase activity despite the presence of a 40 -fold molar surplus of $\alpha_{1} \mathrm{PI}$ antigen in peritonitis exudates.
With resorufin-labeled casein as a substrate, high levels of proteolytic activity were found preferably in exudates with low opsonic capacity (Fig. 8). These findings closely resembled the data obtained from BALF samples in trauma patients (see the chapter by Jochum et al., pp 46-60). In addition to the in vivo and in vitro degradation of $\mathrm{IgG}$ and $\mathrm{C} 3$, we have successfully proven the in vivo generation of FEP in peritonitis exudates of 21 patients. As depicted in Fig. 9, high levels of complexed PMN elastase coincided with highly elevated FEP in the specimen drawn before surgical treatment of the abdomen of a patient with severe peritonitis. After rinsing the peritoneal cavity with 101 of Ringer's lactate solution both parameters decreased nearly to zero. Yet, as can be seen from the abdominal drainage fluids collected between $0-1 \mathrm{~h}, 1-2 \mathrm{~h}$, and $2-8 \mathrm{~h}$ after operation, the release of PMN elastase started again, inducing also the production of FEP (Fig. 9). These observations may be taken as an indication of a still ongoing inflammatory reaction in this patient.

\section{Conclusions}

Summarizing the data obtained in our clinical studies and those of others on patients suffering from severe postoperative or posttraumatic infections, it could be clearly shown that the release of phagocyte proteinases, PMN elastase and cathepsin $\mathrm{B}$, beyond normal values evoked by the physiological turnover of the phagocytes correlated well with the activation of proteolytic clotting enzymes, the consumption of proteinase inhibitors, and the onset and severity of the acute inflammatory reaction.

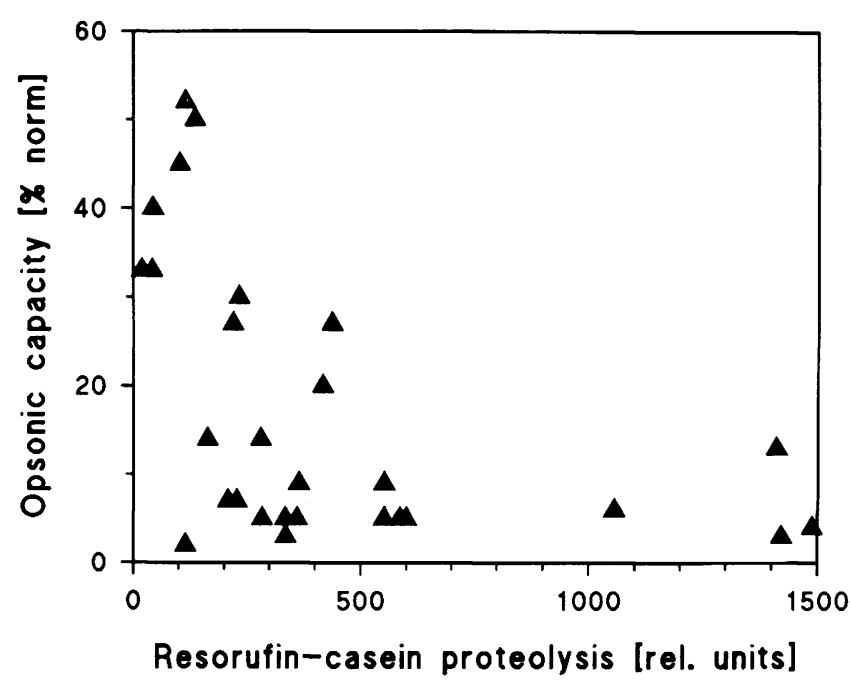

Fig. 8. Opsonic capacity ( $\%$ of the value found with normal serum) and proteolytic activity (measured with resorufin-casein as substrate) of peritonitis exudates $(n=28)$ 
Fig. 9. PMN elastase (in complex with $\alpha_{1}$-proteinase inhibitor) and fibrino-elastase peptide $(F E P)$ in exudate samples taken from a peritonitis patient before (preL) and immediately after (post $L$ ) lavage of the abdomen with Ringer's lactate solution and in drainage fluid collected between $0-1 \mathrm{~h}, 1-2 \mathrm{~h}$, and $2-8 \mathrm{~h}$ after lavage

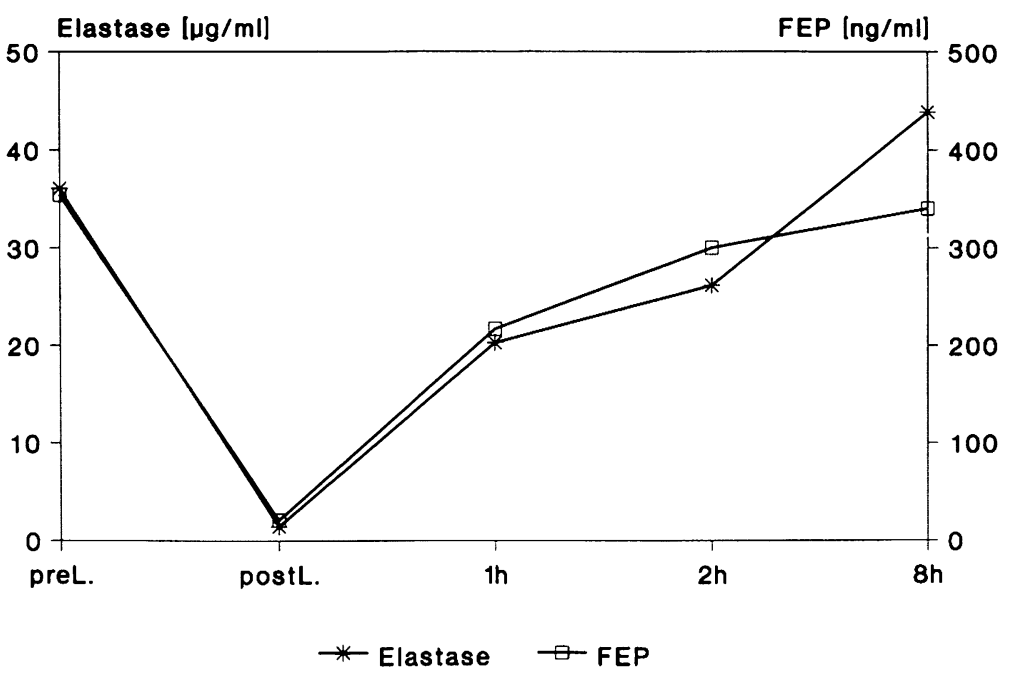

Moreover, the studies showed without doubt that, in patients who have incurred severe infection followed major surgery or trauma, the underlying cellular and humoral biochemical events are quite similar regardless of the etiology of the insult. The clinical outcome seems to be only due to the magnitude of the inflammatory response, which is of course highest when trauma is superimposed by infection (Waydhas et al. 1992).

As outlined in the chapter by Jochum et al. (pp 46-60), the role of PMN elastase as an inflammatory effector seems to be well established. In contrast, the role of the cysteine proteinase cathep$\sin \mathrm{B}$ is less clear. Considering the relatively poor proteolytic action of cathepsin $\mathrm{B}$ on vital proteins in vitro, the destructive potential of cysteine proteinases may be mainly due to cathepsin $\mathrm{L}$ which is likely to be released simultaneously with cathepsin B.

Furthermore, it turned out that discharge of lysosomal phagocyte proteinases and the activation of proteolytic blood cascade enzymes in sepsis and in trauma effected an excessive local $\left(\alpha_{1} \mathrm{PI}\right)$ and systemic (AT III) consumption of proteinase inhibitors. Since these events seem to be the most critical cause allowing proteolysis-induced (multiple) organ failure, supplementation of the body's inhibitor potential by exogenous proteinase inhibitors against elastase and thrombin should be a highly promising approach in treating patients at high risk for septic MOF.

\section{Proteinase Inhibition as a Convenient Therapeutic Approach in Septic Multiple Organ Failure}

If a putative causal mediator in acute inflammation such as septic MOF is, in fact, relevant, the use of specific mediator antagonists as therapeutic tools should prevent, or at least reduce to some extent the severe signs of inflammation, in accordance with Koch-Dale's criterion 4 as indicated by Neugebauer and Lorenz (1988). Since PMN elastase turned out to play a particularly important role in shock-associated organ and hemostasis dysfunctions, we and others envisaged the therapeutic use of elastase inhibitors as the most promising approach to interfere with proteolysis-induced pathomechanisms in acute inflammation (Jochum and Fritz 1990; Fritz et al. 1992; Braun and Schnebli 1986). Moreover, the excessive consumption of AT III during severe inflammatory reactions, which enables unrestricted hemostatic proteinase activity further intensifying the overall pathological proteolysis, should be compensated for by the exogenous administration of potent thrombin inhibitors (Vinazzer 1987; Markwardt 1991; Bichler and Fritz 1991).

Before administering such drugs to humans, especially drugs of nonhuman origin generated by gene technology or chemical synthesis, safety and efficacy has first to be demonstrated in convenient animal models. Thus, progress in sepsis research continues to depend upon studies using clinically relevant animal models which fulfill commonly accepted criteria of the sepsis syndrome.

The working definition of the sepsis syndrome, applicable to both human and laboratory studies, 
comprises a constellation of clinical and laboratory findings indicative of a generalized inflammatory response leading to acute organ dysfunctions often, but not invariably, associated with the presence of serious bacterial, fungal, or viral infection. Furthermore, the septic shock phase is characterized by circulatory decompensation (i.e., hypotension) due to an exacerbation of the septic syndrome.

\section{Inhibitors of Polymorphonuclear Granulocyte Elastase or Thrombin in Experimental Septic/Endotoxin Shock}

\section{Choice of a Convenient Animal Model}

To achieve a clinic-like situation in an experimental setting, a variety of different approaches have been used (extensively reviewed by Fink and Heard 1990). Of those, i.v. infusions of viable bacteria or simply endotoxins (the main toxic cell wall constituents of gram-negative bacteria) are the most common. Although there are considerable doubts about the absolute clinical relevance of these approaches (e.g., because of differences in the hemodynamic responses depending on the amount of the deleterious agent and the administration period), experimental bacteremia or endotoxinemia may nonetheless provide a reasonable paradigm for sepsis in humans, given the proviso that the animal model chosen adequately replicates those features of the clinical syndrome which should be explored in the experiment (e.g., release of phagocyte proteinases in relation to organ dysfunctions).

With respect to the relevant animal species selected in the different laboratory models of sepsis and septic shock, nonhuman primates and pigs have proven to be invaluable in the exploration of the underlying pathobiochemical mechanisms, because of the obvious similarities of these animals to humans concerning physiology and biochemical reactions. Thus Egbring and Havemann (1978) reported that a bolus infusion of $50 \mu \mathrm{g}$ Staphylococcus abortus equi endotoxin $/ \mathrm{kg}$ body weight in a green monkey induced not only the release of PMN elastase (demonstrated semiquantitatively by one-dimensional immunoelectrophoresis) within 20-300 min after the endotoxin injection, but also a concomitant decrease in activity of several coagulation factors, quite similar to findings in septic patients (Egbring et al. 1986; Seitz et al. 1987; Egbring and Havemann 1978). Due to the antigenic identity of many plasma and cellular proteins, the application of a modified version of the ELISA test system for human PMN elastase also allows the exact quantification of the granulocyte proteinase in plasma of baboons. As shown recently by Redl et al. (1991) using this test system, continuous i.v. administration of live Escherichia coli over $8 \mathrm{~h}$ in 7 baboons evoked a massive release of PMN elastase within $1 \mathrm{~h}$ after starting the experiment up to the end of the observation period. Although normal plasma levels of extracellularly discharged PMN elastase in baboons reached only one-third that of humans, the 20 - to 30 -fold increase in septic animals was highly comparable to the situation in septic patients.

Though the baboon model provides the most human-like situation in an experimental setting, pigs are normally preferred as experimental animals because of ethical and financial restrictions in many laboratories. Yet, in contrast to granulocytes of humans and nonhuman primates, porcine PMNs contain both proteolytic and inhibitory activities. As shown by Geiger and colleagues (see review by Geiger et al. 1988) the main inhibitory activity against lysosomal neutral serine proteinases such as elastase is a cytosolic serine proteinase inhibitor (SERPIN)-like protein called leukocyte neutral proteinase inhibitor (LNPI). This inhibitor is released simultaneously with elastase due to stimulation or disintegration of the PMN cells and inhibits effectively the elastolytic enzyme outside of the granulocytes. Thus, using a specifically developed ELISA test system, quantification of the elastase-LNPI complex in porcine plasma turned out to be a reliable measure of the extracellularly discharged PMN constituents (Geiger et al. 1988). Mean plasma levels of this complex in healthy pigs reached $16 \pm 11 \mathrm{ng} / \mathrm{ml}$. In a preliminary study of 8 septic pigs, up to 25 -fold higher levels were observed during the development of septicemia induced by a $2 \mathrm{~h}$ infusion of live $E$. coli (Geiger et al. 1988). Maximal values were measured about $10 \mathrm{~h}$ after the end of the bacterial administration. These results could be clearly confirmed in a second randomized trial, in which the release of the porcine PMN constituents were highly correlated with the occurrence of hypotension and hypoproteinemia due to infusion of viable bacteria (Siebeck et al. 1989a). In another prospectively controlled, randomized, short-term study performed by our research group (Hoffmann et al. 1990), a similar significant increase of PMN elastase in complex with LNPI to above normal was noticed concomitant with the development of organ dysfunctions in 18 pigs receiving a continuous infusion of $S$. abortus 
equi endotoxin over the whole observation period of $6 \mathrm{~h}$. No such changes occurred in sham-treated control animals.

In addition to serving as a model for PMN elastase release in septic/endotoxic situations, pigs are the only animal species in which an extracellular discharge of the monocyte/macrophagederived cysteine proteinase cathepsin $\mathrm{B}$ above normal after endotoxin infusion has been reliably demonstrated (Assfalg-Machleidt et al. 1990; Siebeck et al. 1991). Starting from a normal level of about $200 \mathrm{mU} / 1$ (corresponding to 4-fold that of normal values in healthy humans) i.v. infusion of $S$. abortus equi endotoxin for $6 \mathrm{~h}$ in 19 pigs evoked a steady increase of cathepsin B in plasma up to 3.5fold that of normal at the end of the $6 \mathrm{~h}$ observation period (Assfalg-Machleidt et al. 1990). Concomitant with this increase a significant decrease in arterial blood pressure occurred, indicating a severe septic shock state. In contrast, sham-treated control animals $(n=7)$ did not show any remarkable pathophysiological changes. Similar results could be demonstrated in another randomized trial with 11 pigs also receiving a $6 \mathrm{~h}$ continuous infusion of S. abortus equi endotoxin (Siebeck et al. 1991). In this study the endotoxin-induced rise of cathepsin $\mathrm{B}$ was partially reduced in 13 animals treated with the platelet activating factor (PAF) receptor antagonist WEB 2086 compared with the 11 septic untreated controls, indicating that cathepsin B release may have been mediated to some extent by PAF in the experimental setting.

\section{Results of Inhibitor Therapy}

in Septic/Endotoxemic Pigs

In a preliminary controlled study on $E$. coli sepsis in young pigs, the prophylactic administration of the relatively specific recombinant elastase inhibitor eglin $c$ (originally isolated from the leech Hirudo medicinalis) caused a significant reduction in the consumption of AT III and other plasma proteins as well as in the formation of interstitial pulmonary edema (Jochum et al. 1987). As assessed by measurement of arterial blood pressure and total protein concentration in plasma, Siebeck et al. $(1989 a, b)$ demonstrated in a more extended study that eglin c can also reduce hypotension and the overall capillary leakage induced by the infusion of live $E$. coli into pigs. In this study, significantly lower concentrations of the elastase-LNPI complex in plasma were measured under eglin $c$ administration, presumably indicating extreme rapid competi- tion of the exogenous elastase inhibitor with the granulocyte-derived serine proteinase antagonist LNPI (Siebeck et al. 1989a). Such a rapid complexation by eglin c seems to prevent proteolytic activity of released elastase more effectively than by the endogenous inhibitor.

Moreover, in a further controlled investigation, Siebeck et al. (1989c) and Hoffmann et al. (1990) could show that, besides eglin c, the thrombinspecific inhibitor hirudin - another recombinant inhibitor also formerly isolated from the medical leech - significantly improved endotoxin shock syndromes in minipigs. Fibrinogen consumption, formation of fibrin monomers, the occurrence of pulmonary vasoconstriction, and the release of PMN constituents were clearly lower in endotoxemic animals treated prophylactically with hirudin than in those without continuous intravenous inhibitor infusion. Since hirudin does not interfere with PMN elastase inhibition by endogenous inhibitors, the conclusion can be drawn that the activation of clotting enzymes, which are known as potent, direct or indirect stimulators of PMN cells (Wachtfogel et al. 1983, 1985; Lo et al. 1988), was effectively reduced by inhibition of thrombin, thus also lowering the stimulation of PMN granulocytes.

Interestingly, supplementation of a purified AT III-heparin complex in another randomized porcine endotoxin shock model had only a slight, insignificant, positive effect on endotoxin-induced mortality and oxygen saturation in arterial blood (as an indication of pulmonary function), although the consumption of fibrinogen and the formation of soluble fibrin monomers were clearly prevented in the drug-treated animals (Spannagl et al. 1991). Furthermore, prothrombin consumption was similar in the treatment and placebo groups suggesting that local thrombin generation via factor $\mathrm{Xa}$ and binding of both enzymes to endothelial cell membrane receptors may protect them from inhibition by the AT III-heparin complex. However, the amount of the AT III-heparin complex may not have been sufficient to inhibit activation of contact phase enzymes (plasma kallikrein, factor XIIa) which are supposed to be potent stimulators of PMN granulocytes (Wachtfogel et al. 1983, 1985) as mentioned before. Therefore, the inflammatory process might have been maintained primarily via the release of phagocyte proteinases and reactive oxygen metabolites. Moreover, since after an initial rise (up to about 130\%) the AT III activity decreased during further drug administration while the antigen level still increased, the heparin in the com- 
plex may have facilitated inactivation of AT III by released PMN elastase (Jordan et al. 1989), thereby lowering the inhibitory capacity under an otherwise presumably effective threshold level.

The requirement of high levels of AT III inhibitory activity in the circulation is also confirmed by results of Emerson et al. (1989) concerning the efficacy of AT III supplementation in several animal models (rat, sheep, baboon) of fulminant $E$. coli endotoxemia or bacteremia. Only very high doses (up to 3-fold that of normal) and prophylactic administration of AT III prevented organ damage and increased permanent survival in the experimental animals. Interestingly, the combined application of AT III and $\alpha_{1}$ PI showed a significant synergistic improvement of pulmonary function compared to single drug treatment in the endotoxemic sheep model. This indicates again that a complex interaction of lysosomal and humoral blood cascade proteinases contributes to the perpetuation of a septic-like inflammation.

\section{Systemic Supplementation of Antithrombin III in Clinical Sepsis}

Beside the therapeutic animal experiments, preliminary clinical studies (reviewed by Vinnazer 1987, Seitz et al. 1989, Schwartz et al. 1989) have also proven the postulated positive effects of thrombin inhibition on the hemostatic system by AT III supplementation in severely ill patients. Yet, a statistically significant reduction in MOF or lethality compared to untreated patients could be verified in only a few trials. In these studies just normal plasma levels of AT III were achieved by the therapeutic regimen, infusing purified human AT III concentrates. Thus, we draw the conclusion that only AT III levels well above the normal plasma range may be able to interfere with phagocytederived inflammatory reactions, thereby improving not only disseminated intravascular coagulation but also organ dysfunctions in clinical sepsis. In addition, this assumption is especially supported by our animal experiments (Spannagl et al. 1991) and those of Emerson et al. (1989).

We, therefore, conducted a prospective randomized study (clinically directed by Dr. Inthorn, Department of Surgery Großhadern) of septic patients with the aim to increase the AT III inhibitory activity at least above $120 \%$ that of normal. To achieve this, AT III concentrates were i.v. infused twice daily over 21 days according to a modified regimen originally described by Blauhut et al. (1985). Blood samples were taken twice daily throughout the whole observation period. Preliminary data and a detailed outline of the performance of the still ongoing trial have been published by Jochum et al. (1991). Here, only the most important results will be presented. Up to now, 30 patients, all fulfilling the above mentioned septic criteria, could be enrolled in the control $(n=15)$ and therapy groups $(n=15)$.

With our administration scheme the AT III activity in the treatment group was elevated to mean plasma levels slightly below $120 \%$ during the first 9 days followed by an increase above $120 \%$ thereafter, whereas in the control group levels between $60 \%$ (early phase) and $80 \%$ (later phase) were measurable. Although all AT III-treated patients received nearly the same amount of the inhibitor concentrate (between 8000 and 4000 units per day), those individuals who survived the septic event showed clearly higher AT III levels (up to a mean of $135 \%$ during the first 5 days after sepsis diagnosis) than patients who died despite AT III supplementation (mean AT III activity between $100 \%$ and $115 \%$ in the early septic phase) (Fig. 10). Thus, immediate AT III substitution in sufficiently high amounts after early diagnosis of a septic episode appears to be of great importance in improving the survival of the patients.

Probably due to a too late onset of inhibition therapy along with administration of still insufficiently high AT III doses in some of our patients, the overall mortality could be reduced only from $87 \%$ in the control group to $60 \%$ in the AT IIItreated collective. This diminution in lethality was statistically not significant, yet a clear improvement of organ functions - especially of lung, liver, and kidney - in the treated patients and a further deterioration in the control group became evident.

Mean plasma levels of complexed elastase were elevated up to 6-fold that of normal upon admission and decreased gradually to about 3 -fold in both groups until the end of the observation period. Although there were no statistically significant differences, a slight trend to lower plasma elastase levels appeared in the AT III group. In contrast, an obvious reduction of complexed elastase in plasma due to AT III supplementation was demonstrated by Seitz et al. (1989).

In our study, plasma prekallikrein and prothrombin levels were highly reduced, up to $30 \%$ and $50 \%$, respectively, upon sepsis diagnosis and showed a more or less pronounced change to higher values ( $40 \%$ and $80 \%$ that of normal) later on without distinct differences in the placebo and treatment groups (Fig. 11). Interestingly, however, 
Fig. 10. Mean values of antithrombin III inhibitory activity (measured as \% of NP = Normal Plasma in plasma of septic patients treated with AT III; survivors $(n=6)$; nonsurvivors $(n=9)$

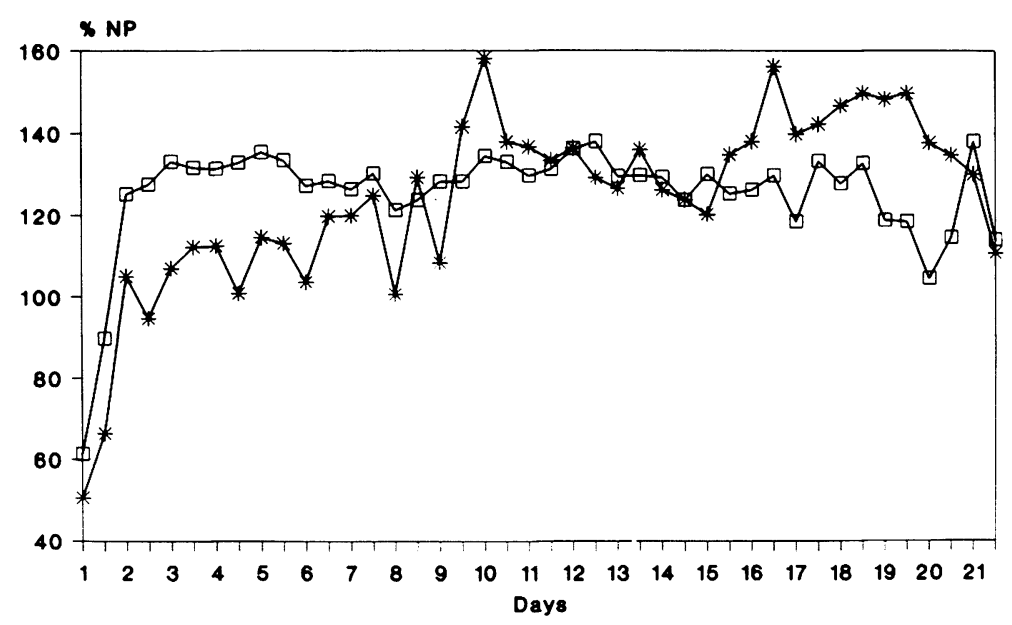

non-survivors survivors

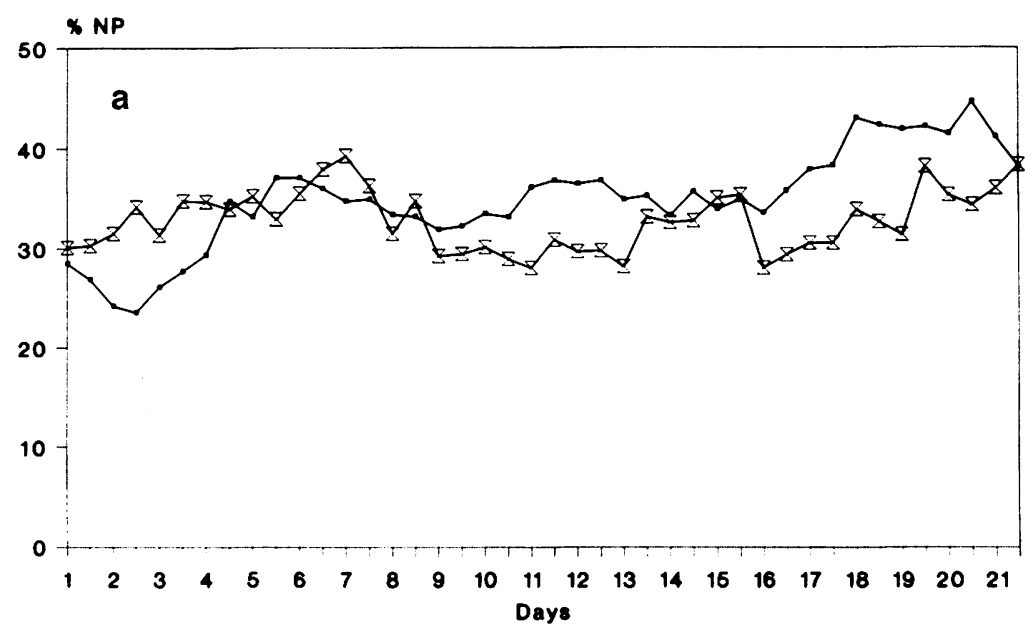

$\rightarrow$ AT III (n-16) $\approx$ Control $(n-16)$

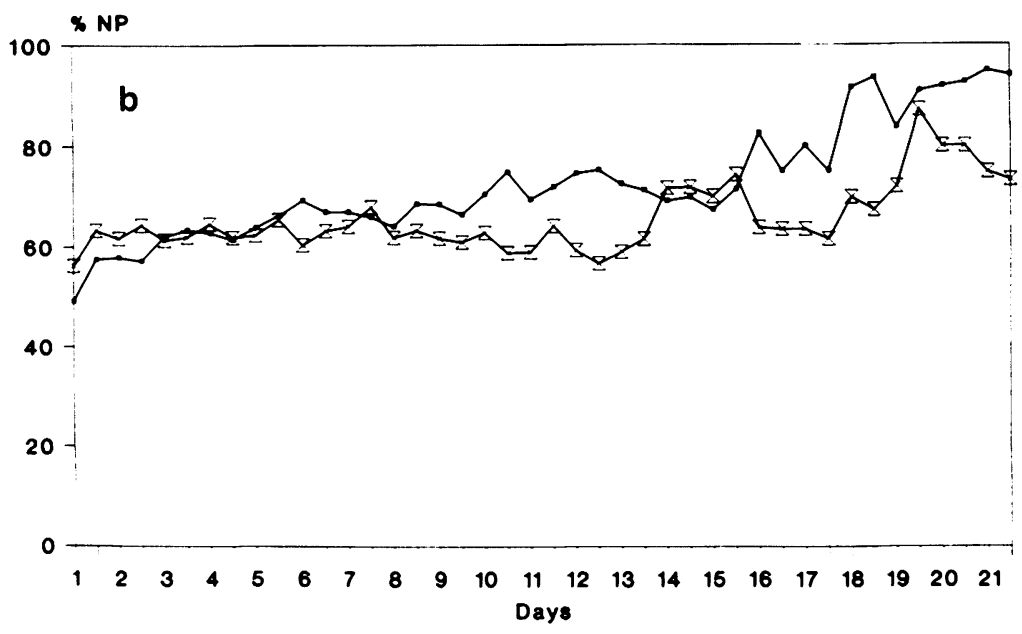

$\longrightarrow$ AT III $(n-16) \quad$ Eontrol $(n-16)$
Fig. 11. Mean values of prekallikrein (a) and prothrombin (b) in plasma of septic patients treated $(n=15)$ and not treated $(n=15)$ with AT III; $\% \mathrm{NP}=\%$ of Normai Plasma 
prekallikrein levels rose steadily up to $50 \%$ in AT III-treated survivors, whereas in the nonsurvivors a further transient decrease up to $20 \%$ occurred (Fig. 12). An analogous behavior was observed for prothrombin, which reached $80 \%$ that of normal 10 days after onset of sepsis in the AT III-treated survivors, while in the moribund patients plasma prothrombin levels as low as $60 \%$ were measured at that time. Thus, the rise in AT III inhibitory activity to nearly $140 \%$ in the early septic phase may have been beneficial enough to preserve clotting proenzymes from excessive activation throughout a septic period. Nevertheless, it became obvious from our findings that a convincing improvement of the overall septic state deserves an even higher and earlier substitution of AT III than that used in this study.

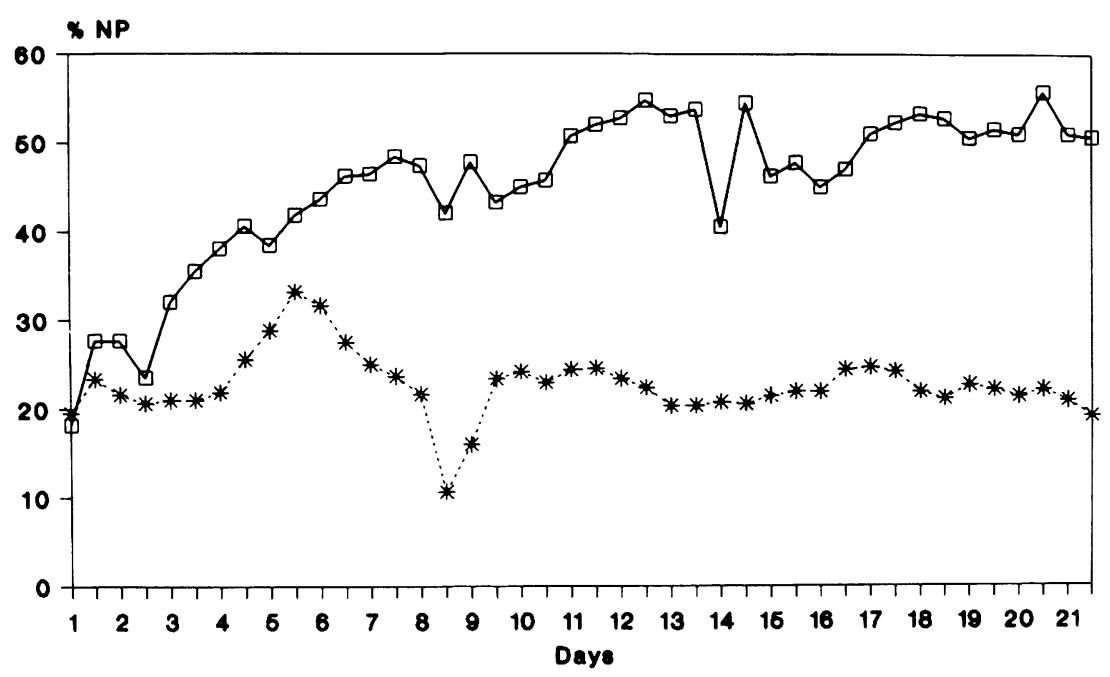

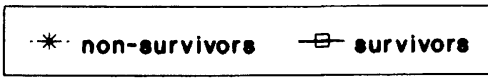

\section{Local Administration of Serum in Peritonitis}

In diffuse peritonitis, phagocytosis of bacteria is impaired by the drastically diminished opsonic capacity of the exudate due to proteolytic (and oxidative?) inactivation of the major opsonins $\operatorname{IgG}$ and complement factor C3 (see above). Intraabdominal administration of serum, containing both high amounts of intact opsonins and a broad spectrum of proteinase inhibitors, should improve the situation. In a pilot study Billing et al. (1991) observed an increased opsonic capacity when $300 \mathrm{ml}$ of blood bank serum was instilled into the abdominal cavity at the end of the operation procedure and lavage of the whole abdomen with 101 of Ringer's lactate solution. Just recently, these preliminary results were confirmed in a controlled study involving 15 patients receiving serum after lavage and 15 controls lavaged without subsequent serum application (Billing 1992). Exudate samples were drawn before and after abdominal lavage and
Fig. 12. Mean values of prekallikrein in plasma of septic patients treated with AT III; survivors $(n=6)$; nonsurvivors $(n=9) ; \% \mathrm{NP}=\%$ of Normal Plasma from the postoperative drainage fluid collected between $0-1 \mathrm{~h}, 1-2 \mathrm{~h}$, and $2-8 \mathrm{~h}$ after operation. After rinsing the abdominal cavity with Ringer's lactate solution, the reduced opsonic capacity of the exudate increased only slightly in the control group, whereas in the therapy group with subsequent intraabdominal administration of $300 \mathrm{ml}$ serum a highly significant improvement of opsonic capacity was observed over $8 \mathrm{~h}$ (Fig. 13). The higher opsonic capacity of the exudate determined in the ex vivo samples correlated with microbiological data indicating an enhanced elimination of bacteria and an improved clinical outcome of the patients in the therapy group (Billing 1992).

In addition, we found a marked difference between $\alpha_{1}$ PI antigen and inhibitory activity (measured against trypsin) in the primary exudates of both the serum and the control groups indicating 
that part of the inhibitor was inactive due to oxidation and/or proteolytic cleavage (Fig. 14). This difference was abolished by rinsing the abdomen even without serum administration, but significantly higher postoperative $\alpha_{1}$ PI levels were reached and sustained in the serum group. After operation and abdominal lavage the proteolytic activity of the drainage fluid measured with resorufin-casein as substrate was greatly reduced but not completely

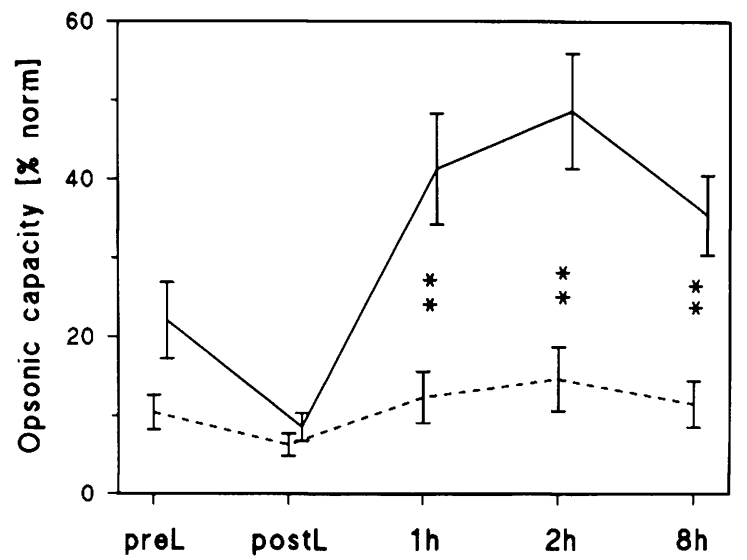

Fig. 13. Effect of intraabdominal serum administration on the opsonic capacity of peritonitis exudates (in $\%$ of the value obtained with normal serum). Samples were taken before (preL), immediately after (post L) lavage of the abdomen with Ringer's lactate solution and postoperatively from drainage fluids collected between $0-1 \mathrm{~h}, 1-2 \mathrm{~h}$, and $2-8 \mathrm{~h}$ after lavage. Values are given as mean $( \pm \mathrm{SEM})$ for control $(n=15$, dotted line $)$ and serum-treated $(n=15$, solid line) patients; $* *$ differences statistically significant $(p<0.01)$

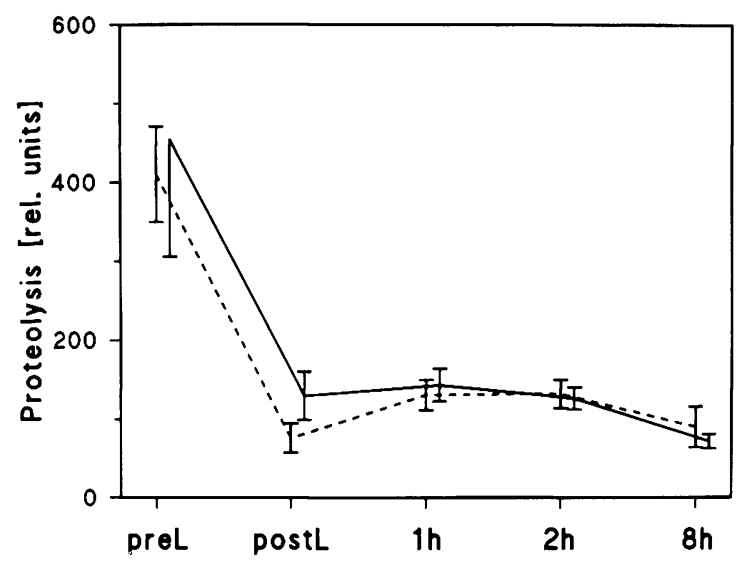

Fig. 15. Effect of intraabdominal serum administration on the proteolytic activity in peritonitis exudates; measured with the substrate resorufin-casein. For further details see Figs. 13 and 14 abolished (Fig. 15). Serum administration seemed to slow down the reincrease of proteolytic activity, but the differences compared to the control group were not statistically significant. Thus, proteinase inhibition by the given amount of serum may not be sufficient, and additional supplementation of proteinase inhibitors should be envisaged to improve the therapeutic effect.

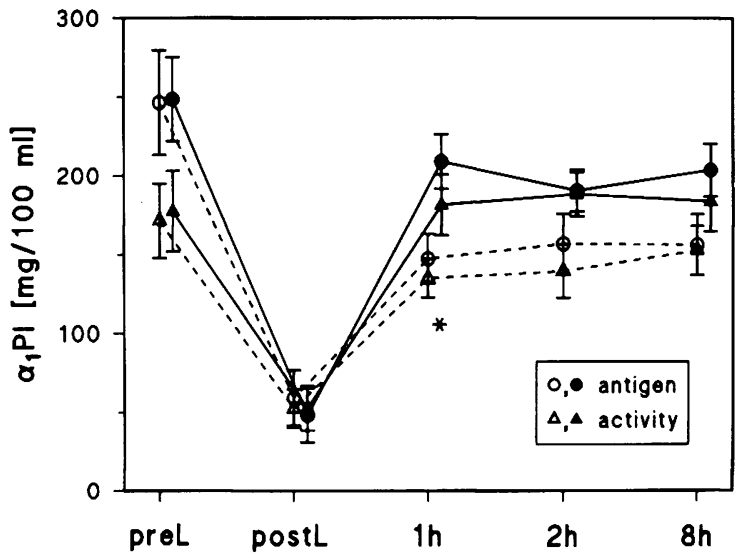

Fig. 14. Effect of intraabdominal serum administration on $\alpha_{1}$-proteinase inhibitor $\left(\alpha_{1} \mathrm{PI}\right)$ antigen concentration and inhibitory activity in peritonitis exudates. Values are given as mean $( \pm \mathrm{SEM})$ for control $(n=15$, dotted line) and serum-treated ( $n=14$, solid line) patients. For sample collection see Fig. 13; *, statistically significant $(p<0.05)$ difference between $\alpha_{1} \mathrm{PI}$ antigen concentrations of serum group and control group

\section{Conclusions}

The data derived from the therapeutic experimental and clinical studies on acute inflammation unequivocally indicate that proteolytic pathomechanisms due to phagocyte and hemostasis proteinases play an important role in the onset and perpetuation of inflammatory processes such as sepsis-induced multiple organ dysfunctions. Therefore, plasma levels of regulatory elastase and thrombin inhibitors have to be elevated by a suitable supplementation and kept well above the normal inhibitory activity in healthy people to achieve a significant improvement of the clinical situation in severely ill patients.

Despite the fact that the leech-derived elastase and thrombin inhibitors eglin $c$ and hirudin have shown a high efficacy in animal experiments, their clinical use has to be considered with caution, especially concerning the putative antigenicity of 
nonhuman proteins in long-term studies. Thus, a therapeutic approach with isolated, purified, human plasma inhibitor preparations $\left(\alpha_{1} \mathrm{PI}, \mathrm{AT}\right.$ III) is the only clinical choice at present.

The natural sources for the isolation of proteinase inhibitors from human material are very limited. Thus, molecular modeling to design highly effective inhibitory proteins on the basis of human inhibitor molecules and their production by recombinant DNA technology is the most promising approach to get the quantities necessary for proteinase inhibition therapy in the future (Fritz et al. 1992).

\section{Summary}

Several years ago, Neugebauer et al. (1987) outlined in detail more than 100 different mediators that were causally related to acute inflammation and circulatory shock. Despite or probably because of the fact that none of these factors have yet been unequivocally shown to be of ultimate relevance, there is still a growing number of new mediators which have been proposed as playing the central role in an acute inflammatory process such as multiple trauma and sepsis. To establish, however, a cause-effect relationship for a single mediator of shock, the classical criteria of Koch-Dale for being a causal chemical factor in a pathological reaction should be considered in a modified version using metaanalysis and models of decision trees as suggested by Neugebauer et al. (1987) and Neugebauer and Lorenz (1988).

Since not a single factor but rather a mixture of causal inflammatory mediators act in concert to evoke a sepsis-like syndrome following severe trauma (see the chapter by Jochum et al., pp 46-60), major surgery, or infection, we have been especially interested in the extent that proteolytic pathomechanisms may participate in the initiation and perpetuation of these acute inflammatory processes. Although we did not use meta-analysis procedure and models of decision trees in detail, a more or less narrative review of our research and that of other authors with respect to the topic of interest revealed a prominent role for proteinases in acute inflammation. This statement is based on the following evidence:

1. Release of the lysosomal phagocyte proteinases, PMN elastase and monocyte/macrophage-derived cathepsin $\mathrm{B}$, and activation of proteolytic blood cascade enzymes in proportion to the severity of trauma-, surgery-, and/or bacteria-in- duced inflammation could be clearly verified in a variety of clinical studies. Moreover, the amounts of the extracellularly discharged phagocyte proteinases in plasma at an early stage of the disease were highly predictive for forthcoming organ failure and ultimate outcome.

2. The consumption of proteinase inhibitors $\left(\alpha_{1} \mathrm{PI}\right.$, AT III) and other plasma proteins susceptible to proteolytic degradation coincided with the occurrence of proteolytic activity, especially that of PMN elastase.

3. Split products of functional proteins specifically generated by the phagocyte proteinases could be demonstrated in local and systemic human body fluids correlating with the extracellular release of these enzymes.

4. The therapeutic use of specific PMN elastase or thrombin inhibitors in experimental septic/endotoxin shock or clinical sepsis, respectively, prevented or at least reduced to some extent severe signs of inflammation.

Yet, despite these convincing data, ultimate assessment of the relevance of proteolytic enzymes in shock states, notwithstanding the numerous other candidate mediators, requires application of the probabilistic model suggested by Neugebauer and Lorenz (1988), i.e. showing that the factor of interest is a necessary, sufficient, or contributory determinant.

Acknowledgements. We are very grateful to be participating clinical colleagues mentioned in the text for their intensive collaborations. Part of our work was financially supported by the Sonderforschungsbereich 207 of the University of Munich (grants G5 to MJ and G1 to WM).

\section{References}

Assfalg-Machleidt I, Jochum M, Nast-Kolb D, Siebeck M, Billing A, Joka Th, Rothe G, Valet G, Zauner R, Scheuber HP, Machleidt W (1990) Cathepsin B - indicator for the release of lysosomal cysteine proteinases in severe trauma and inflammation. Biol Chem Hoppe Seyler 371 [Suppl]:211-222

Bichler J, Fritz H (1991) Hirudin, a new therapeutic tool? Ann Hematol 63:67-76

Billing A (1992) Untersuchungen zur intraabdominalen Abwehrfunktion bei der menschlichen Peritonitis und ihre therapeutische Beeinflußbarkeit. Habilitationsschrift, Med. Faculty of the LM-University of Munich

Billing A, Fröhlich D, Jochum M, Kortmann H (1988a) Impaired phagocytosis in peritonitis exudate secondary to complement consumption. Surg Res Commun $3: 335-345$ 
Billing A, Fröhlich D, Jochum M, Kortmann H (1988b) Deficient phagocytosis secondary to proteolytic breakdown of opsonins in peritonitis exudate. Adv Exp Med Biol 240:441-448

Billing A, Kortmann H, Fröhlich D, Jochum M (1989) Breakdown of C3 complement and IgG in peritonitis exudate - pathophysiological aspects and therapeutical approach. Prog Biol Res 308:527-533

Billing A, Fröhlich D, Assfalg-Machleidt I, Machleidt W, Jochum M (1991) Proteolysis of defensive proteins in peritonitis exudate: pathobiochemic aspects and therapeutic approach. Biomed Biochim Acta 50:399-402

Blauhut B, Kramer H, Vinazzer H, Bergmann H (1985) Substitution of antithrombin III in shock and DIC. A randomized study. Thromb Res 39:81-89

Braun NJ, Schnebli HP (1986) A brief review of the biochemistry and pharmacology of eglin c, an elastase inhibitor. Eur J Respir Dis 146 [Suppl]:541 - 547

Duswald K-H, Jochum M, Schramm W, Fritz H (1985) Released granulocytic elastase: an indicator of pathobiochemical alterations in septicemia after abdominal surgery. Surgery 98:892-898

Egbring R, Havemann K (1978) Possible role of polymorphonuclear granulocyte proteases in blood coagulation. In: Havemann K, Janoff A (eds) Neutral proteases of human polymorphonuclear leukocytes. Urban and Schwarzenberg, Baltimore, pp 442-455

Egbring R, Seitz R, Blanke H, Leititis J, Kesper HJ, Burghard R, Fuchs G, Lerch L (1986) The proteinase inhibitor complexes (antithrombin III-thrombin, $\alpha_{2}$-antiplasmin-plasmin and $\alpha_{1}$-antitrypsin-elastase) in septicemia, fulminant hepatic failure and cardiac shock: Value for diagnosis and therapy control in DIC/F syndrome. Behring Inst Mitt 79:87-103

Emerson TE, Fournel MA, Redens TB, Taylor FB (1989) Efficacy of antithrombin III supplementation in animal models of fulminant Escherichia coli endotoxemia or bacteremia. Am J Med 87 [Suppl 3B]:27-33

Fink MP, Heard SO (1990) Laboratory models of sepsis and septic shock. J Surg Res 49:186-196

Fink PC, Suin de Boutemard C, Gaitzsch A (1988) Determination of endotoxemia and leukocyte elastase in patients with septicemia. GIT Labor-Medizin 7-8:409-415

Fink PC, Erdmann R, Schöndube F, Baca I (1989) Leukocytes, neutrophilia, and elastase- $\alpha_{1}$-proteinase inhibitor-complex: marker of different validity for monitoring the perioperative infection risk. Prog Clin Biol Res 308:695-700

Fritz H, Collins J, Jochum M (1992) Proteinase inhibitor candidates for therapy of enzyme-inhibitor imbalances. In: Grassi C, Travis J, Casali L, Luisetti M (eds) Current concepts in the biochemistry of pulmonary emphysema. Springer, Berlin Heidelberg New York/Bi and Gi, Verona Publishers, pp 101-112

Frommherz KJ, Faller B, Bieth JG (1991) Heparin strongly decreases the rate of inhibition of neutrophil elastase by $\alpha_{1}$-proteinase inhibitor. J Biol Chem 266:15356-15362
Geiger R, Sokal S, Siebeck M, Hoffmann H, Trefz G (1988) Determination of leukocyte elastase-inhibitor complexes and leukocyte neutral proteinase inhibitor by enzyme immunoassays. J Clin Chem Clin Biochem 26:605-609

Gippner-Steppert C (1991) Entwicklung eines spezifischen Testsystems für den Nachweis der Bildung eines proteolytischen Spaltproduktes des Fibrinogens durch lysosomale PMN-Elastase sowie Untersuchungen am Miniplasminogen, einem Elastase-spezifischen Spaltprodukt des Plasminogens. Dissertation, Chem. Faculty of the Technical University of Munich

Glauser MP, Zanetti G, Baumgartner JD, Cohen J (1991) Septic shock: pathogenesis. Lancet 338:732-735

Hoffmann H, Siebeck M, Spannagl M, Weipert J, Geiger R, Jochum M, Fritz H (1990) Effect of recombinant hirudin, a specific inhibitor of thrombin, on endotoxin-induced intravascular coagulation and acute lung injury in pigs. Am Rev Respir Dis 142:782-788

Inthorn D, Jochum M (1988) Auswirkungen chirurgischer Infektionen auf die Stimulierbarkeit zur Chemilumineszenz von Granulozyten und die Freisetzung granulozytärer Elastase. In: Häring R (ed) Risiko in der Chirurgie. Analyse und Kalkulation. De Gruyter, Berlin, pp 219-224

Jochum M (1988) Lysosomale Faktoren aus polymorphkernigen Granulozyten: pathobiochemische, diagnostische und therapeutische Aspekte. Habilitationsschrift, Med. Faculty of the LM-University of Munich

Jochum M, Fritz H (1990) Elastase and its inhibitors in intensive care medicine. Biomed Prog 3:55-59

Jochum M, Lander S, Heimburger N, Fritz H (1981) Effect of human granulocytic elastase on isolated human antithrombin III. Hoppe Seyler's Z Physiol Chem 362:103-112

Jochum M, Welter HF, Siebeck M, Fritz H (1987) Proteinase inhibitor therapy of severe inflammation in pigs. First results with eglin, a potent inhibitor of granulocyte elastase and cathepsin G. In: Taylor JC, Mittmann $C$ (eds) Pulmonary emphysema and proteolysis. Academic, Orlando, pp 85-90

Jochum M, Assfalg-Machleidt I, Inthorn D, Nast-Kolb D, Waydhas C, Fritz H (1990) Leukozytäre Proteinasen und Hämostasestörung bei der Sepsis. In: Tilsner V, Matthias R (eds) XXXIIth Hamburger Symposion über Blutgerinnung: Infektion, Entzündung und Blutgerinnung. Editiones Roche, Basel, pp $241-254$

Jochum M, Inthorn D, Nast-Kolb D, Fritz H (1991) AT III - ein neues therapeutisches Konzept bei der Behandlung der Sepsis und beim Organversagen? In: Henschel WF (ed) Blut, Blutkomponenten und Blutersatzstoffe in der Intensivmedizin. Bericht über das 10. Bremer Interdisziplinäre IntensivtherapieColloquium. Zuckschwerdt, Munich, pp 46-58

Jordan RE, Nelson RM, Kilpatrick J, Newgren JO, Esmon PC, Fournel MA (1989) Antithrombin inactivation by neutrophil elastase requires heparin. Am J Med 87 [Suppl 3B]:19-22 
Lo SK, Lai L, Cooper JA, Malik AB (1988) Thrombininduced generation of neutrophil activating factors in blood. Am J Pathol 130:22-32

Machleidt W, Assfalg-Machleidt I, Billing A, Fröhlich D, Jochum M, Joka T, Nast-Kolb D (1993) The role of lysosomal cysteine proteinases as markers of macrophage activation and as non-specific mediators of inflammation. In: Faist E, Meakins J, Schildberg FW (eds) Host Defence Dysfunction in Trauma, Shock and Sepsis. Springer, Berlin Heidelberg, pp 459-463

Markwardt F (guest ed) (1991) Hirudin. Semin Thromb Hemost 17 (2)

Neugebauer E, Lorenz W (1988) Causality in circulatory shock: strategies for integrating mediators, mechanisms and therapies. Prog Clin Biol Res 264:295-305

Neugebauer E, Lorenz W, Maroske D, Barthlen W, Ennis M (1987) The role of mediators in septic/endotoxic shock. A meta-analysis evaluating the current status of histamine. Theor Surg 2:1-28

Pacher R, Redl H, Frass M, Petzl DH, Schuster E, Wolosczuk W (1989) Relationship between neopterin and granulocyte elastase plasma levels and the severity of multiple organ failure. Crit Care Med 17: 221-226

Parrillo JE, Parker MM, Natanson C, Suffredini AF, Danner RL, Cunnion RE, Ognibene FP (1990) Septic shock in humans. Advances in the understanding of pathogenesis, cardiovascular dysfunction, and therapy. Ann Intern Med 113:227-242

Redl H, Schlag G, Bahrami S, Schade U, Ceska M, Stütz P (1991) Plasma neutrophil-activating peptide-1/interleukin- 8 and neutrophil elastase in a primate bacteremia model. J Infect Dis 164:383-388

Schöffel U, Kopp KH, Lausen M, Ruf G, Farthmann EH (1989a) Monitoring of postoperative intraabdominal septic complications following major abdominal surgery. Surg Res Commun 5:49-53

Schöffel U, Zeller T, Lausen M, Ruf G, Farthmann EH (1989b) Monitoring of the inflammatory response in early peritonitis. Am J Surg 157:567-572

Schwartz RS, Bauer KA, Rosenberg RD, Kavanaugh EJ, Davies DC, Bogdanoff DA (1989) Clinical experience with antithrombin III concentrate in treatment of congenital and acquired deficiency of antithrombin. Am J Med 87 [Suppl 3B]:53-60

Seitz R, Wolf M, Egbring R, Radtke KP, Liesenfeld A, Pittner P, Havemann K (1987) Participation and interactions of neutrophil elastase in haemostatic disorders of patients with severe infections. Eur J Haematol 38:231 - 240

Seitz R, Wolf M, Egbring R, Havemann K (1989) The disturbance of hemostasis in septic shock: role of neutrophil elastase and thrombin, effects of antithrombin III and plasma substitution. Eur J Haematol $43: 22-28$
Shimanuki K, Sakurabayashi I, Kanazawa K (1989) Perioperative fluctuation in plasma levels of granulocyte elastase and alpha-1-antitrypsin: the influence of the severity of surgical intervention and their effect on the respiratory index. Jpn J Surg 19:410-417

Siebeck M, Hoffmann H, Geiger R, Schweiberer L (1989a) Leukocyte neutral proteinase inhibitor of the pig: Modification by eglin $\mathrm{c}$ and superoxide dismutase of the response to shock. Prog Clin Biol Res 308:945-951

Siebeck M, Hoffmann H, Jochum M, Fritz H (1989b) Inhibition of proteinases with recombinant eglin $\mathrm{c}$ during experimental Escherichia coli septicemia in the pig. Eur Surg Res 21:11-17

Siebeck M, Hoffmann H, Weipert J, Spannagl M (1989c) Therapeutic effects of the combination of two proteinase inhibitors in endotoxin shock of the pig. Prog Clin Biol Res 308:937-943

Siebeck M, Weipert J, Keser C, Kohl J, Spannagl M, Machleidt W, Schweiberer L (1991) A triazolodiazepine platelet activating factor receptor antagonist (WEB 2086) reduces pulmonary dysfunction during endotoxin shock in swine. J Trauma 31:942-949

Spannagl M, Hoffmann $H$, Siebeck $M$, Weipert J, Schwartz HP, Schramm W (1991) A purified antithrombin III-heparin complex as a potent inhibitor of thrombin in porcine endotoxin shock. Thromb Res $61: 1-10$

Speer CP, Tegtmeyer F (1989) Elastase- $\alpha_{1}$-proteinase inhibitor in neonatal infections, hyaline membrane disease and meconium aspiration. In: Cosmi EV, di Renzo GC (eds) Proceedings of the XIth European congress of perinatal medicine. Harwood, Chur, pp $852-858$

Tanaka H, Sugimoto H, Yoshioka T, Sugimoto T (1991) Role of granulocyte elastase in tissue injury in patients with septic shock complicated by multiple organ failure. Ann Surg 213:81-85

Tsaka T, Herkner KR (1990) Polymorphonuclear elastase in neonatal sepsis. Clin Chim Acta 193:103-112

Vinazzer H (1987) Clinical use of antithrombin III concentrates. Vox Sang 53:193-198

Wachtfogel YT, Kucich U, James HL, Scott CF, Schapira M, Zimmerman M, Cohen A, Colman RW (1983) Human plasma kallikrein releases neutrophil elastase during blood coagulation. $\mathrm{J}$ Clin Invest 72 : $1672-1677$

Wachtfogel YT, Pixley RA, Kucich U, Abrams W, Weinbaum G, Schapira M, Colman RW (1985) Purified plasma factor XIIa aggregates human neutrophils and releases elastase. Circulation 70 [Suppl II]:352

Waydhas C, Nast-Kolb D, Jochum M, Trupka A, Lenk S, Fritz H, Duswald K-H, Schweiberer L (1992) Inflammatory mediators, infection, sepsis, and multiorgan failure after severe trauma. Arch Surg 127:460-467 